Aligning basic to intermediate macroeconomics to current central bank practice - new suggestions and some unfinished business

Jörg Baumberger

March 2003 D iscussion paper no. 2003-10 
Editor:

Publisher:

Electronic Publication:
Prof. Jörg Baumberger

University of St. G allen

Department of Economics

Bodanstr. 1

CH-9000 St. Gallen

Phone ++41712242241

Fax ++41712242885

Email_joerg.baumberger@unisg.ch

Forschungsgemeinschaft für $\mathrm{N}$ ationalökonomie an der U niversität St. Gallen

Dufourstrasse 48

$\mathrm{CH}-9000$ St. Gallen

Phone $\quad++41712242300$

Fax $\quad++41712242646$

www.fgn.unisg.ch/public/public.htm 


\title{
A ligning basic to intermediate macroeconomics to current central bank practice - new suggestions and some unfinished business ${ }^{1}$
}

\author{
Jörg Baumberger
}

$\begin{array}{ll}\text { Author's address: } & \text { Prof. Jörg Baumberger } \\ & \text { University of St. Gallen } \\ & \text { Department of Economics } \\ & \text { Bodanstr. 1 } \\ & \text { CH-9000 St. Gallen } \\ & \text { Tel. } \quad++41712242241 \\ & \text { Fax } \quad++41712242885 \\ & \text { Email joerg.baumberger@ unisg.ch } \\ & \text { W ebsite http://www.vwa.unisg.ch/baumberger/main.html }\end{array}$

${ }^{1}$ Acknowledgements: I have benefited from discussions with André Burgstaller, Patrick Coggi, Manfred $\mathrm{G}$ ärtner, Christian Jaag. All remaining errors are mine, particularly those to which, for lack of simple teacheable alternatives, I continue to stick. 


\begin{abstract}
The present paper aims at providing a framework for teaching macroeconomics at the introductory to intermediate level. In doing this, my principal concern is to align current teaching models with the modern practice of central banking. In the spinit of Romer (1999), I introduce a simple monetary policy rule, which is shown to make the LM curve redundant. This approach is consistent with the more traditional ISLM, but provides a basis for addressing some important stylized facts very early in the course in a straightforward and much more natural way. Particular attention is devoted to issues such as liquidity traps and monetary policy in an open economy. Finally, directions for further improvements are pointed out. I think that the new family of teaching models I present should not crowd out ISLM but rather complement it.
\end{abstract}

\title{
Keywords
}

Teaching of macroeconomics, General aggregate macro models, Monetary policy rules, Monetary policy in an open economy.

\section{JEL Classification}

A22, E00, E52, E58 


\section{Ten commandments for a teaching model of the macroeconomy}

Teaching macroeconomics at the introductory to intermediate level requires more than a thorough knowledge of past and present literature on the subject. Like in any serious scientific discipline student progress is produced in a roundabout process. Learning is investment, but first-time investors require more than a systematic step-by-step introduction to the discipline which, ultimately, will equip them with the tools to tackle real-life problems and understand the academic literature. What is needed are teaching models that lend themselves to produce answers to real life problems at an early stage of their education, albeit at the price of some heroic simplifications. The principles model should be able to handle some stylised problems very early on in the course. On the other hand, the model should also lay the foundation for robust analytical habits that will prove useful at later stages of education. There is no point in being problem-oriented at the price of conveying the feeling that, in economics, the sun rises every day for a different reason. Textbook macro models have to meet several pedagogic criteria of quality.

a) They should provide a coherent framework for analysis of multi-market macroeconomic equilibria, thereby fostering the feeling for interdependencies.

b) They should provide first insights into effects and side effects of macroeconomic policy.

c) They should acquaint the students with the major macroeconomic price and quantity magnitudes.

d) The models should provide training in the handling of a simple formal apparatus without being mere formal exercises. They should lend themselves to at least some eclectic applications. Some principles texts definitely overdo this aspect, though, by suggesting that everything neatly falls into place without ambiguity. Notwithstanding these exaggerations of neatness, introductory texts must benefit from some tolerance regarding scientific rigor in order to elicit interest at an early stage.

e) In order to create good habits, the reference model developed at the end of an introductory course should satisfy what I like to call The Ten Commandments for a good teaching model of the macroeconomy:

The ten ideal desiderata for a good teaching model comprise: 
1. Early on, students should learn how to handle simultaneous multi-market equilibrium (market for goods and services, money market with implicit bond market, labour market, balance of payments equilibrium). They should espouse the idea that the macroeconomy is not the mere juxtaposition of independent "markets", but rather a system with interacting markets.

2. They should get used to some rigorous stock-flow hydraulics, and, hence, dynamics.

3. Likewise, their model ought to contain a rigorous price level/price change mechanics.

4. At some early stage, the role of expectations should become clear through a plausible model of the mechanics of expectations.

5. In its more advanced stages, it should be able to accommodate intertemporal relationships.

6. Rigorous modelling of real and nominal rates

real and nominal interest rates

real and nominal exchange rates

7. Plausible modelling of shocks

shocks in real demand for goods and services

shocks in supply of goods and services

shocks from money supply

shocks from money demand

8. Plausible modelling of aggregate demand management policies

fiscal policy

„monetary policy“ in the sense of once-and-for-all changes in base money

supply or once-and-for-all changes in the base money growth rate

monetary policy in the sense of a monetary policy rule (MPR)

9. Plausible modelling of natural rate hypothesis in the sense of some attractor model of potential output and natural rate of unemployment. Long-run neutrality and superneutrality of money, combined with short-run non-neutrality and nonsuperneutrality of money. 
10. Plausible incorporation of international (current account and capital account) transactions and exchange rates. Plausible integration of fixed and flexible exchange rates.

For nearly fifty years students have been raised on a diet of Keynesian crosses and ISLM models. Few attempts have been made to dethrone the standard model. Hardly had the ISLM model attained canonical status, Brunner and Meltzer (1972) began contesting it by pointing out its shortcomings. In 1984, Barro proposed to replace the traditional ISLM folklore by a rigorous analysis of intertemporal choices. More recently, Stockman (1996) suggested that macroeconomics basically amounts to little more than a generalisation of simple demand and supply graphs of the pizza market and that ISLM was worth at best a single footnote. On a more sophisticated level, Danthine (1998) mounted his assault with a sketch of a process aimed at identifying the objective one is groping for in the Graal-like quest for a successor to the conventional ISLM model. The aim of the amendment proposed by this article is more modest. It discusses the attempts to adapt the traditional model to the contemporary practice of central banks. This endeavour is generally associated with the hope the modification do not complicate the analysis because the new component, the monetary policy rule, is expected to make an old one, the LM curve, redundant.

\section{A textbook macro-model without an LM curve}

Amended basic macro-models for introductory courses have been proposed by Taylor (2001), Frank and Bernanke (2001), and Romer (2000). They can be summarised by 3 equations (all parameters positive):
(1) $Y_{t}=c(1-t) Y_{t}-c T_{0}+G_{0}+\bar{I}-b r_{t}$
IS-curve
(2) $r_{t}=r_{0}+a p_{t}$
Monetary policy rule (MPR)
(3) $p_{t}=p_{t-1}+?\left(Y_{t-1}-Y^{*}\right)$
Short run aggregate supply or inflation adjustment

Variables have their conventional meaning ${ }^{1}$.

\footnotetext{
${ }^{1}$ See list of variables at the end of the paper.
} 
These are three equations in three unknowns: $Y_{t}, r_{t}, p_{t}$. The model is no more difficult to handle than a conventional IS-LM model. It incorporates features that are generally considered essential for a basic understanding of macroeconomic relationships:

1. Inflation appears from the outset as a basic fact of economic life. And deflation constitutes a definite possibility. If care is taken to show that inflation is the first time derivative of a more basic underlying magnitude, viz. the price level, there is no objection to this shortcut.

2. It models sticky inflation. Equation 3 may well be the most economical way of modelling sticky prices.

3. Deviations from potential output are modelled as self-correcting. To be sure, there is here a peculiar kind of self-correction mechanism in that it results from the interaction of markets with a central bank that sticks to a pre-determined rule of monetary policy.

4. Unlike the IS-LM model, it is dynamic from the outset. There is no simultaneity. Note that the notion of inflation is introduced into the model even before the notion of a price level.

Moreover, it provides the simplest conceptualisation of a contingent policy rule. The contingent target real interest rate of the central bank is a positive function of the prevailing rate of inflation. An economist educated in conventional macroeconomics might wonder how we justify the assumption that the central bank controls the real interest rate. The reform authors base their assertion on an argument of differential speeds of adjustment. Indeed, under normal circumstances, the (short-term) interest rate is under the control of the central bank, and prices and inflation are comparatively inert. Given this inertia, one could call the resulting power to manipulate the nominal interest rate with given short-run inflation rate and/or given inflation expectations a power to manipulate the real interest rate. To what extent the real interest rate that is being manipulated in this fashion is the real interest rate that really matters, is an open question. Yet, surely, the assumption of short run control of the real interest rate by the central bank is no more outlandish than what is suggested by conventional IS-LM or SRAS-AD models. 


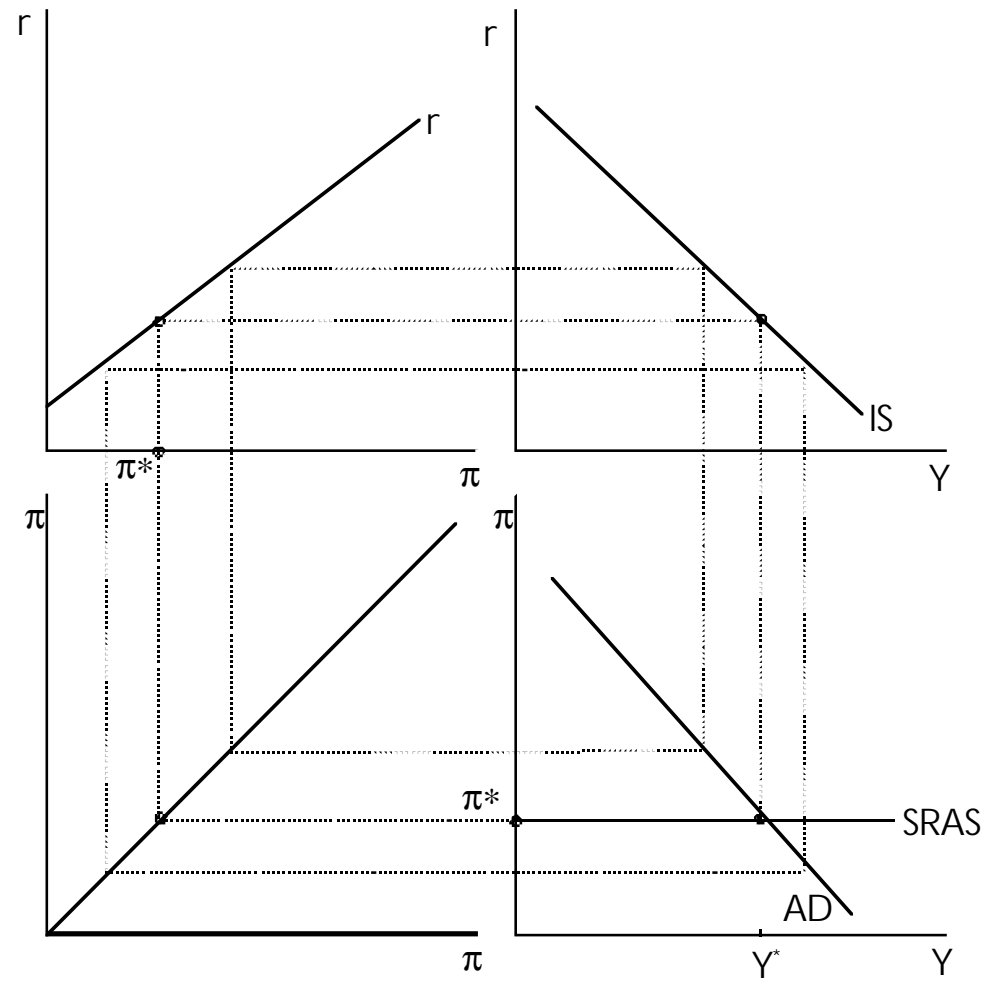

Figure 1: Steady state equilibrium for a closed economy.

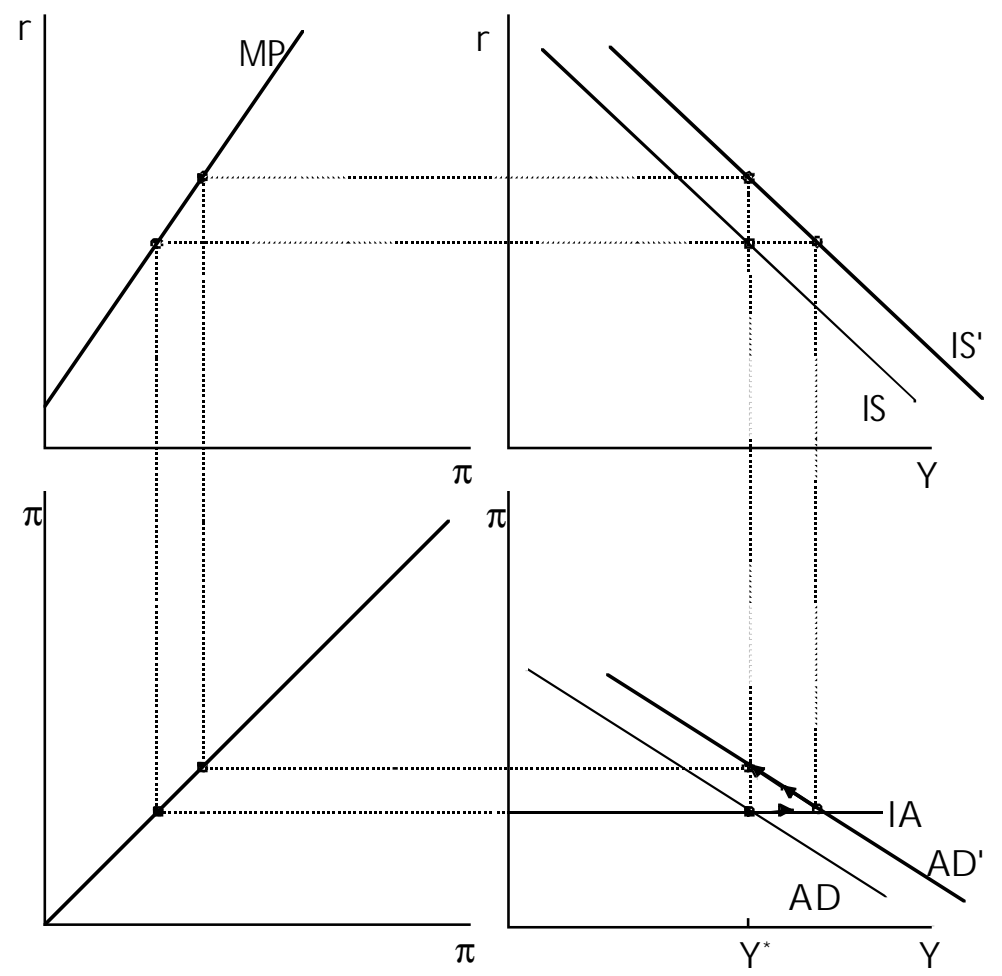

Figure 2: Fiscal shock/impulse 


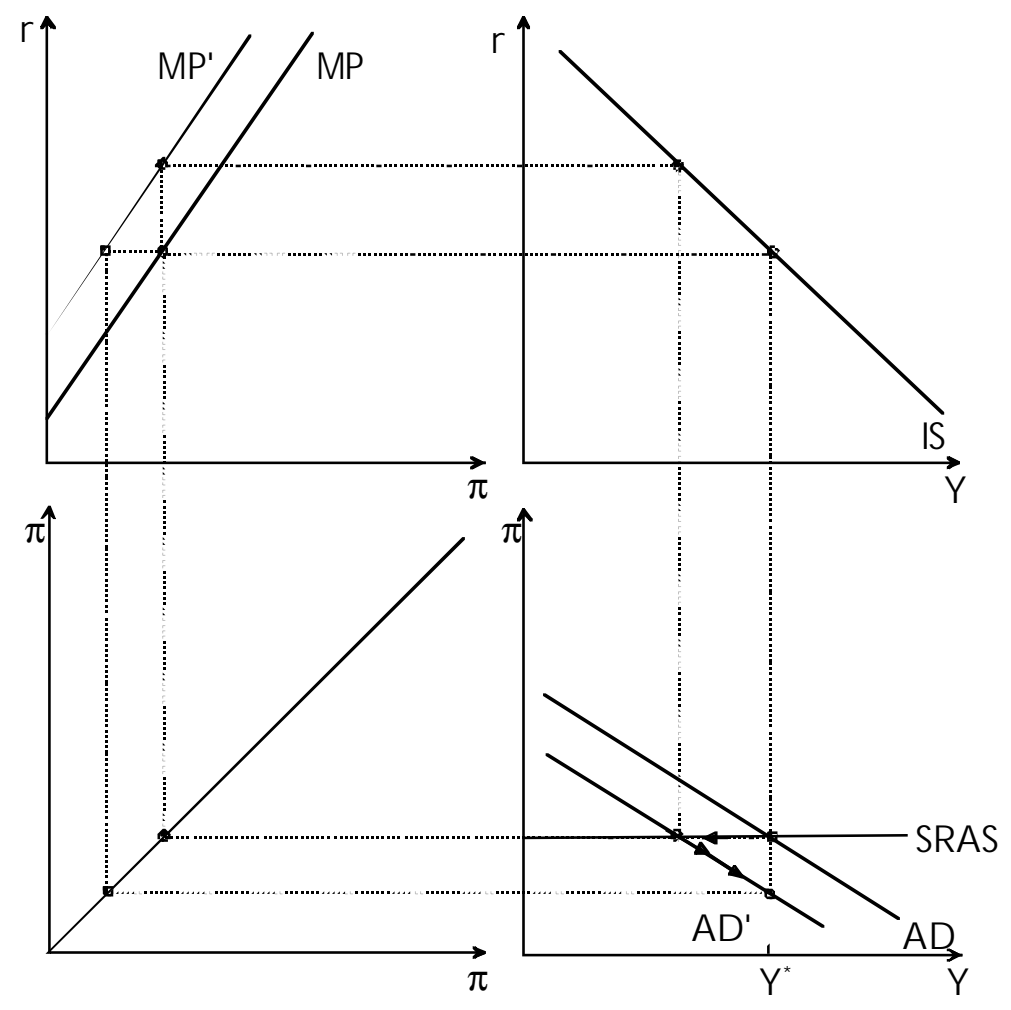

Figure 3: Monetary policy impulse

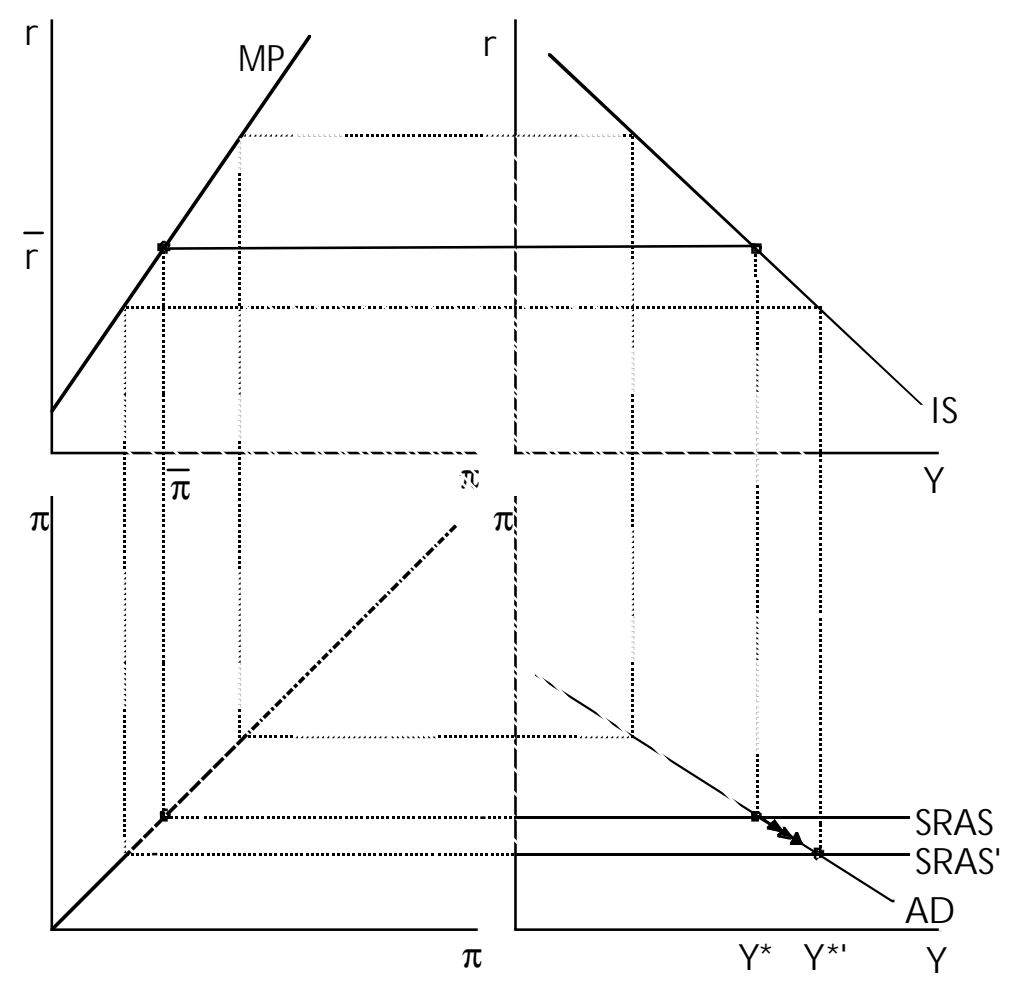

Figure 4: Productivity shock 


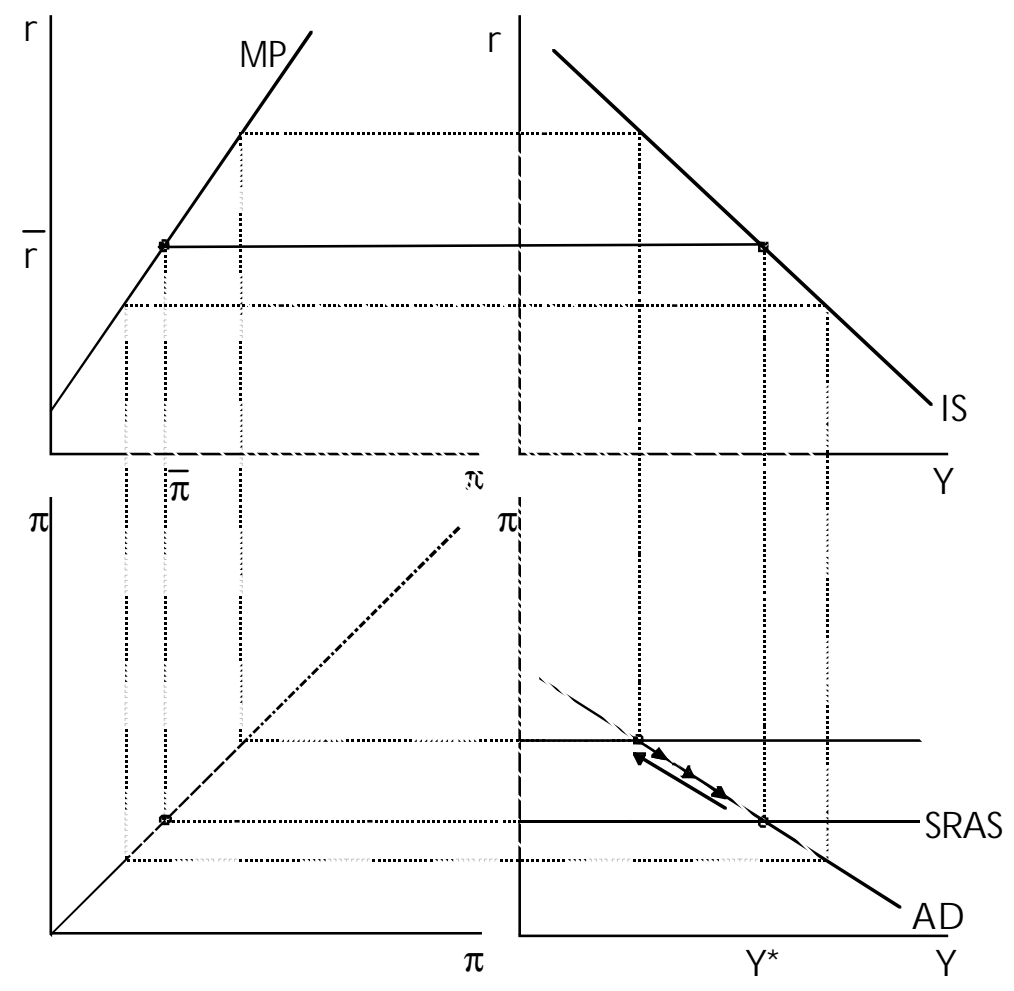

Figure 5: Inflation shock

The behaviour of this economy under various shocks and policy impulses is fairly straightforwand though at first glance it may seem strange to a student educated on conventional IS-LM folklore. In any case, model response to standard textbook shocks and exogenous policy impulses is reasonable and consistent with what one would anticipate.

Shocks to the real final demand for goods and services move the IS curve and hence the $\mathrm{AD}$ curve. The initial response will be purely quantitative. Subsequently, inflation and the real interest rate adjust, leading to an new steady state inflation and real (and nominal) interest rate. This is very similar to what we know from ISLM, or more precisely "aggregate demand-aggregate supply“ macro models, with one important difference: the adjustment path is co-determined by the MPR. It also makes sense that the steady state real variables are independent of the monetary policy (i.e. the MPR). In the steady state, the MPR affects only the inflation rate and the (implicit) nominal interest rate, i.e. only nominal variables. Changes in the MPR have repercussions on the AD curve, just as a change in the LM curve does, but since they leave the IS curve (and $Y^{*}$ ) unaffected, their comparative steady state effect is entirely nominal, i.e. on inflation. This is as it should be. 
What the model does not convey is an idea of what happens if the central bank "does nothing", i.e. leaves the base money supply where it happens to be. Consequently, it also leaves unclarified the behaviour of the economy under simple monetary growth rules. To demonstrate under such a monetary framework inevitably requires an explicit model of the money market, particularly of money demand. If, however, it is true that central banks always ultimately act via monetary accommodation of a momentary interest target, then the loss of generality stemming from short-circuiting the money market via an MPR may be a forgivable sin.

\section{Inserting an MPR model into an IS-LM or AS-AD model}

At some point, the student, particularly one educated on IS-LM, will want to know how this relates to the money market which, in the benchmark model remains invisible. This link is easy to establish. Indeed, there is no contradiction between the IS-MPR model and a traditional IS-LM or AS-AD model. One merely has to add four equations: a money demand equation, a Fisher relation, a money market equilibrium, and an equation trivially defining the price level

(4) $Y_{t}=c(1-t) Y_{t}-c T_{0}+G_{0}+\bar{I}-b r_{t}$

IS curve

(5) $L_{t}=k Y_{t}-h i_{t}$

Money demand

(6) $r_{t}=r_{0}+a p_{t}$

Monetary policy rule (MPR)

(7) $i_{t}=r_{t}+p_{t}$

Fisher relation

(8) $\quad M_{t}^{s}=L_{t} P_{t}$

Monetary accommodation

(9) $p_{t}=p_{t-1}+?\left(Y_{t-1}-Y^{*}\right)$

Short-run aggregate supply

(10) $P_{t}=P_{t-1}\left(1+\pi_{t}\right)$

Inflation definition

This brings the model to 7 equations in 7 unknowns: $Y_{t}, r_{t}, L, i, p_{t}, M_{t}^{s}, P_{t}$.

Equations (4), (6), and (9) form the "core" of the model, the remaining four equations constituting mere „appendices“. Those appendices ensure price level-inflation consistency and keep track of the perfectly passive money supply. Equations (4) and (6) combine to yield the aggregate demand curve in the conventional nomenclature, 
i.e. the locus of the twin equilibria, in the market for goods and services and in the money market. The model can easily accommodate more elaborate commodity supply processes as well as more sophisticated monetary policy rules.

The IS-MPR model can easily be depicted by a five quadrant-diagram. Addition of an extra line in the MPR part of the diagram enables one to distinguish between real and nominal interest rate at a very early stage. In onder to show the monetary accommodation that takes place behind the scenes, a fifth quadrant can be added.

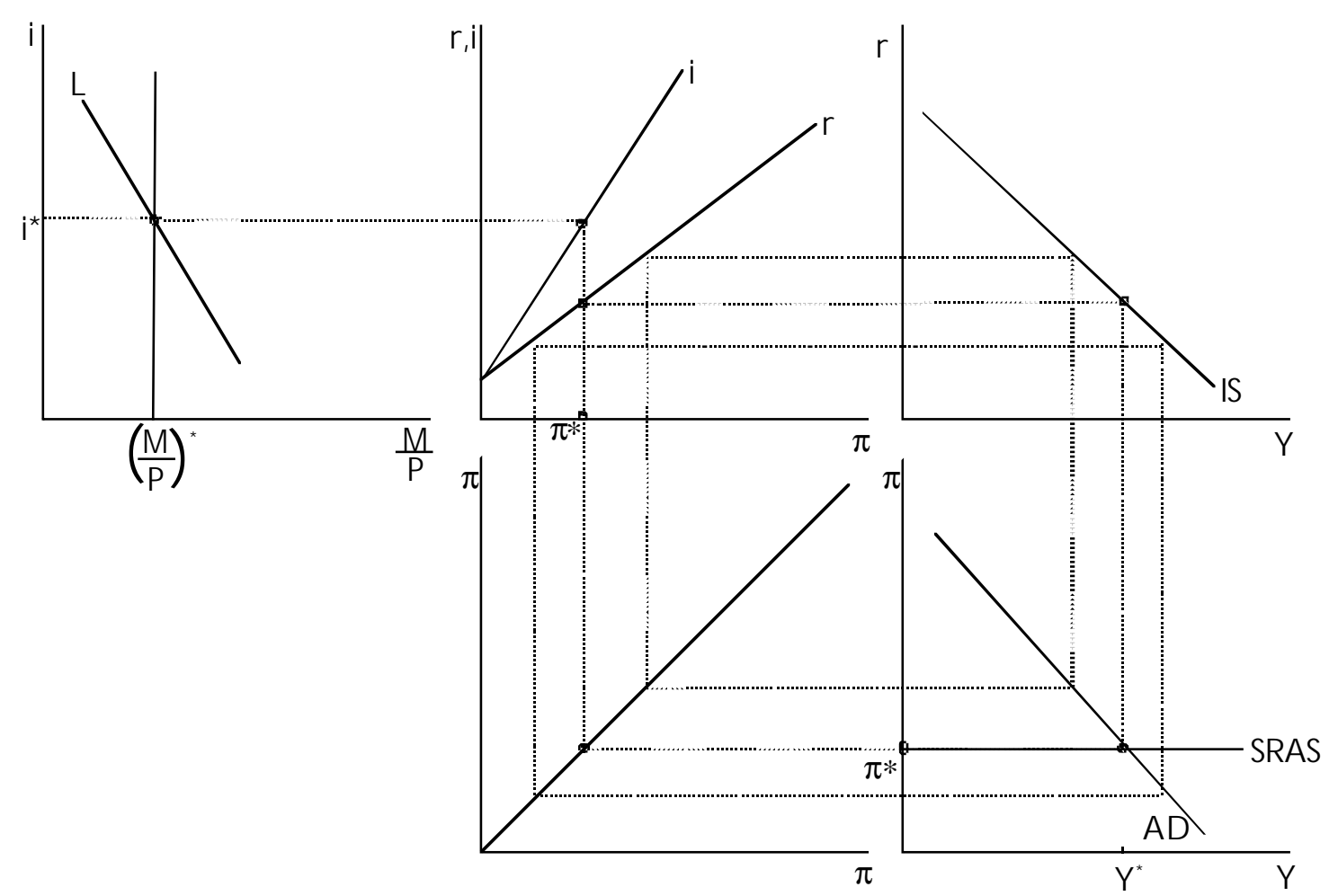

Figure 6: Steady state equilibrium of closed economy with money market
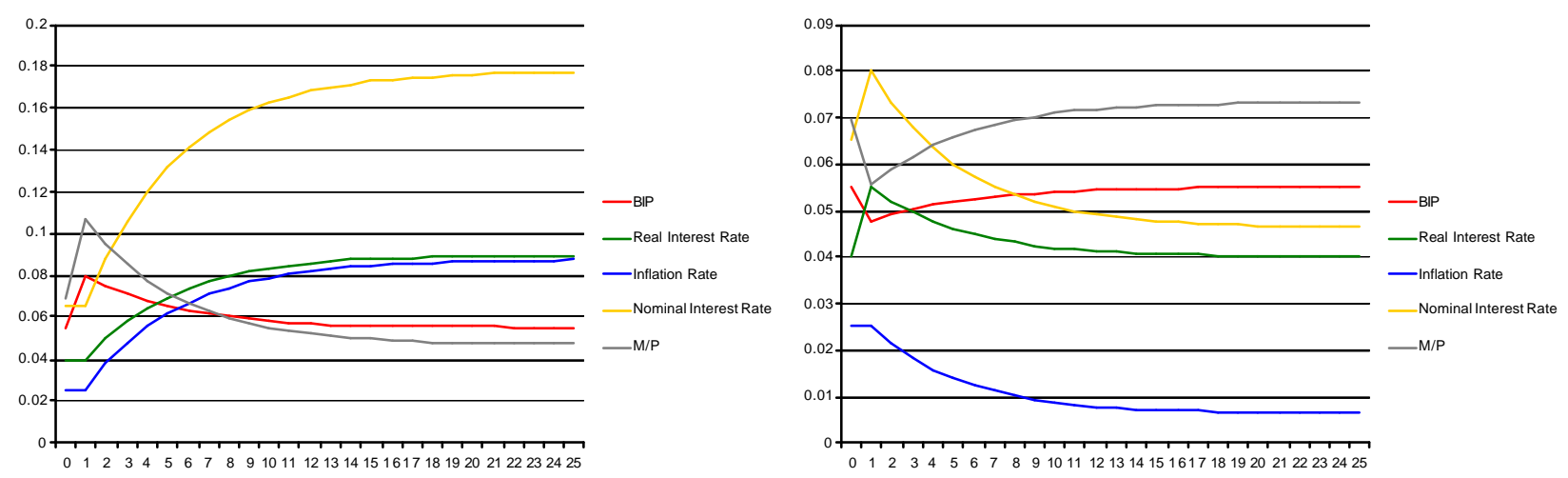

Figure 7: Demand shock and change in the MPR 
A different way of specifying the MPR consists in making the real interest rate depend not on the rate of inflation but rather on output, or, more precisely, on the output gap.

(11) $r_{t}=r_{0}+d\left(Y_{t}^{-} Y^{*}\right) \quad M P R$

This specification simplifies the graphic representation in that the MPR now appears in (Y,r)-space, much like a regular LM-curve. A model of this type may have been in the back of Romer's mind when developing his model for the open economy (Romer 1999).
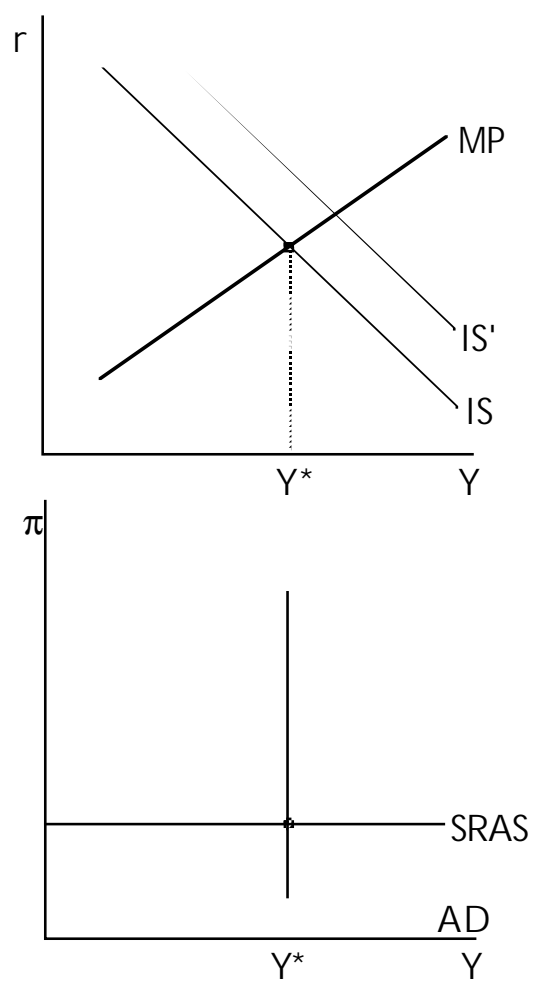

\section{Figure 8: Steady state with gap-driven MPR}

A problem with this specification stems from the fact that the attainment of a constant steady state rate of inflation is no longer ensured. Indeed, a shift of the IS curve will move equilibrium away from $Y^{*}$, and there is no mechanism any more for bringing output back to potential. Output stays put above potential and inflation keeps increasing. This does not mean that there is anything inherently "wrong“ with the model, it just describes a very unlikely monetary policy, viz. one that totally ignores inflation. It should come as no surprise that a monetary policy rule that completely neglects inflation will exhibit this kind of behaviour. 


\section{Improving the SRAS curve}

Instead of the simple SRAS curve, one could resort to a conventional SRAS curve.

(12) $p_{t}^{e}=p_{t-1}^{e}+\theta\left(\pi_{t-1}-\pi_{\mathrm{t}-1}^{e}\right) \quad$ Inflation expectations

(13) $\pi_{t}=\pi_{t}^{e}+\lambda\left(\mathrm{Y}_{t}-Y^{*}\right) \quad$ SRAS

This results in an extra equation and an extra unknown. The basic logic of the model remains unaffected, though, since the only difference with respect to the preceding approach is that the short-run aggregate supply curve now has positive slope.

$\pi_{\mathrm{t}}=\pi_{\mathrm{t}-1}^{\mathrm{e}}+\theta\left(\pi_{\mathrm{t}-1}-\pi_{\mathrm{t}-1}^{\mathrm{e}}\right)+\lambda\left(\mathrm{Y}_{\mathrm{t}}-\mathrm{Y}^{*}\right)$

Yet, this modification is irrelevant for the qualitative results. 


\section{The IS-MPR model with a Taylor rule}

How about a monetary policy rule in the shape of a complete Taylor rule? Does this alter the analysis? The rule is generally formalised in terms of an inflation and an income component.

$$
r_{t}=r_{0}+a p_{t}+d\left(Y_{t}-Y^{*}\right)
$$

This extension of the rule does not fundamentally change the analysis. Indeed, the simple MPR of the preceding sections can be represented as a map of horizontal isoinflation curves in the $\left(Y_{t}, r_{t}\right)$-space. The MPR is a two-dimensional contingent rule. It incorporates an implicit target inflation rate. This can be seen by representing the inflation term in the shape of iso-inflation curves. The value of the IS curve at income $Y^{*}$ determines the real interest rate and the steady state inflation rate. The latter corresponds to the inflation rate of the iso-inflation line going through the steady state income and real interest rate point.

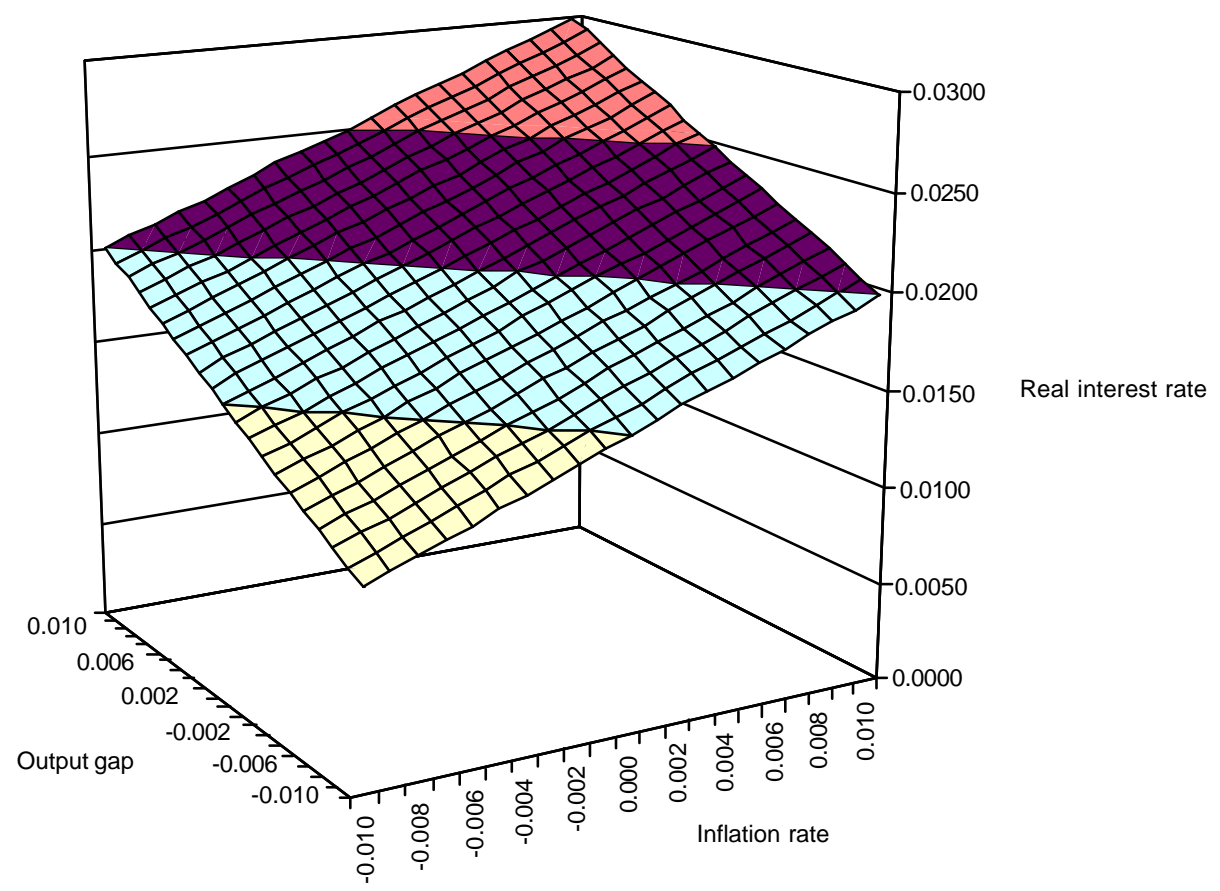

Figure 9: A Taylor rule 


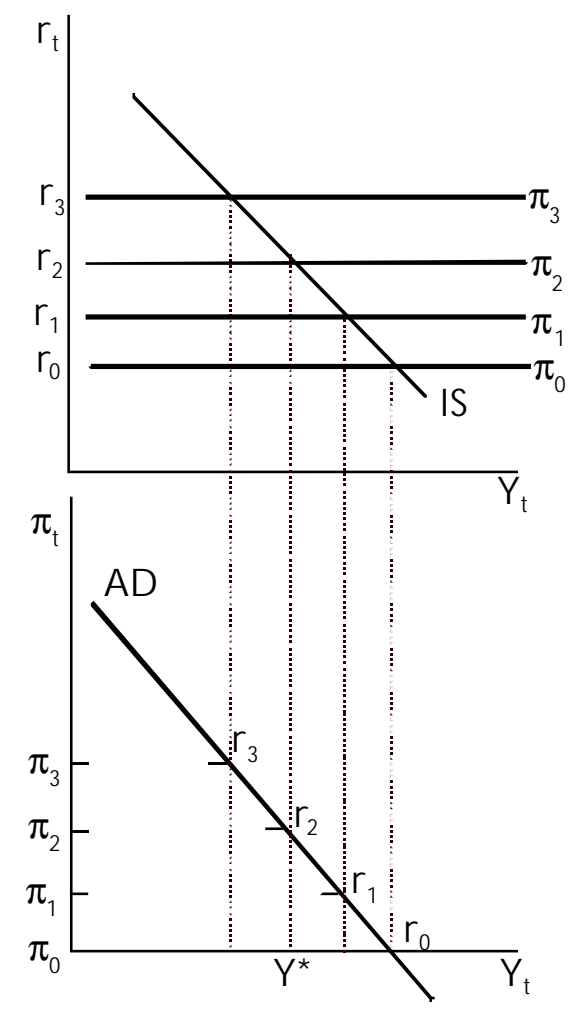

Figure 10: IS and AD curves with simple MPR

Adding an income term to the MPR amounts to giving a positive slope to the isoinflation curves. These curves now remind one of regular LM-curves, but they are not, of course. First, they are iso-inflation, not iso-price-level curves, and second, they do not reflect market responses to inflation but rather central bank responses to inflation. Thus, they translate directly into an AD-curve. Ordinary LM-curves reflect a given particular supply of central bank money. Here, the supply of central bank money is endogenous. 


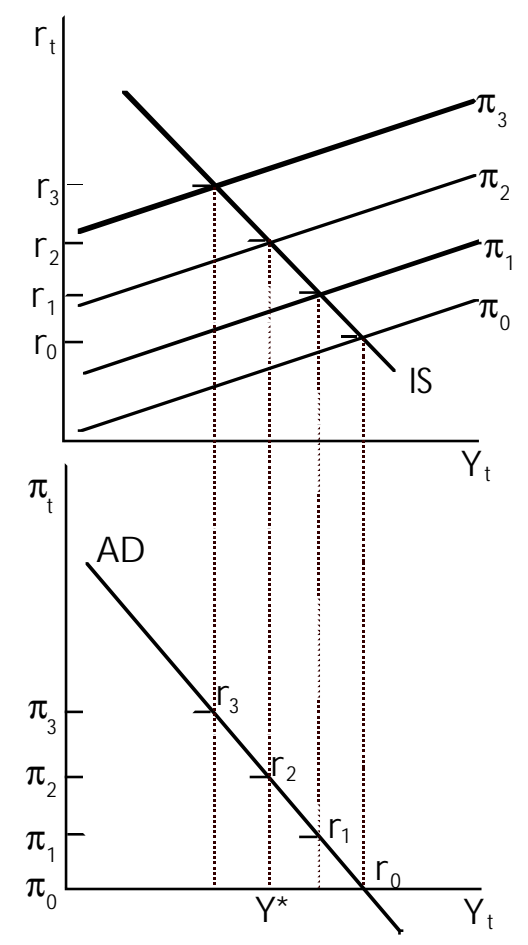

\section{Figure 11: IS and AD curves with a full Taylor rule in $\left(Y_{t}, r_{t}\right)$ space}

Increasing the parameter representing the inflation reactivity of the real interest rate means increasing the distance between two iso-inflation curves. This makes the ADcurve flatter. Increasing the constant term of the MPR amounts to moving the entire map of iso-inflation curves up, which moves the AD-curve downwards. Introduction of the new argument into the MPR does affect the slope of the AD-curve; the steady state real interest rate and, of course, the steady state income remain unaffected. Thus, in the long run, in the context of this short run model, monetary policy still affects only steady state inflation and the speed of convergence to the steady state. Output and the real interest rate remain unaffected.

A comparison between graphs 10 and 11 reveals that an output gap-augmented MPR does not significantly alter the mechanics of the model outlined earlier, either.

Fig. 12 shows the response of the system to a shift in the IS curve. As is easily seen, this shifts the $\mathrm{AD}$ curve to the right. The only difference with the preceding simple MPR consists in the fact that the impact effect on income is smaller because the rise in output beyond $Y^{*}$, via the Taylor rule's third term, immediately raises the real interest rate. This effect, however, is purely incidental. It owes more to the quite arbitrary lag structure than to the essence of the expanded MPR. At any rate, the return to the 
steady state will be, ceteris paribus, be faster given the extra term than it would be without it.

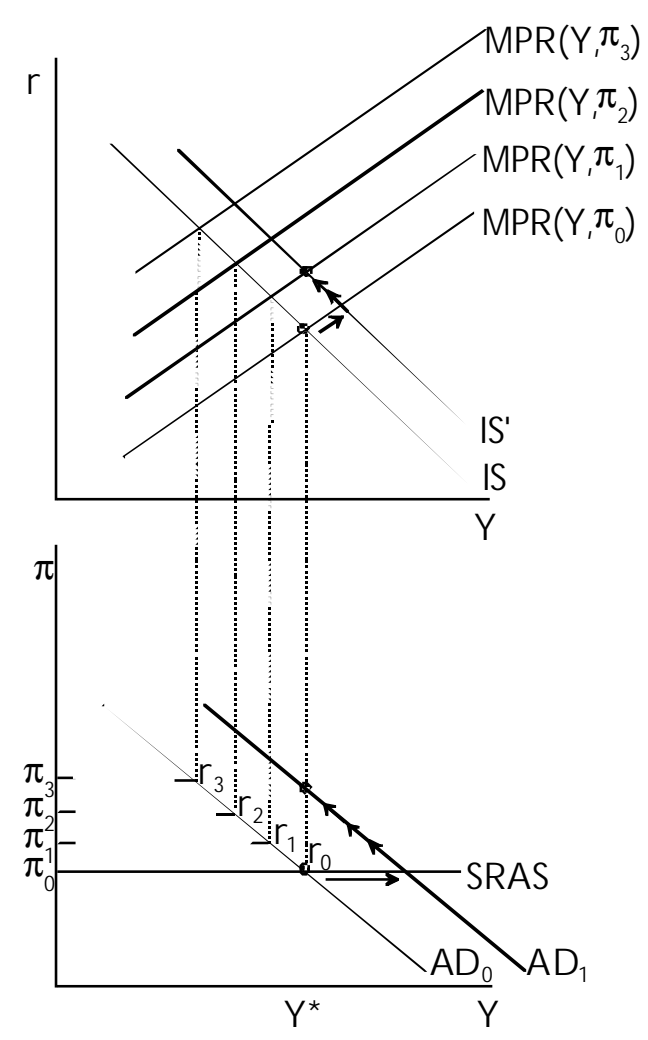

Figure 12: A shift of the IS curve under an expanded MPR (Taylor rule)

The Taylor rule can also be used for the purpose of central bank watching. Assuming that the central bank uses a standard Taylor rule with both parameters equal to 0.5, and using the nominal form of the rule, we can infer the fluctuations in the implicit inflation rate. The nominal version of the MPR is constructed via the Fisher law:

(15) $i_{t}=r_{t}+p_{t}$

Thus, the rule in nominal terms reads:

(16) $i_{t}=r_{0}+(1+a) p_{t}+d\left(Y_{t}-Y^{*}\right)$

While, for the fed, the unknown to be computed is $i_{t}$, the unknown for the fed watcher is $\bar{p}_{t}$.

(17) $\bar{p}_{t}=\left[i_{t}-r_{0}-d\left(Y_{t}-Y^{*}\right)\right] \frac{1}{1+a}$ 
Given the assumption that $r_{0}=2.5$ per cent, ${ }^{2}$ the formula can be used to evaluate the current monetary stance of the central bank. A high $\bar{p}_{t}$ indicates an expansionary MPR, a low $\bar{p}_{t}$ indicates a restrictive stance.

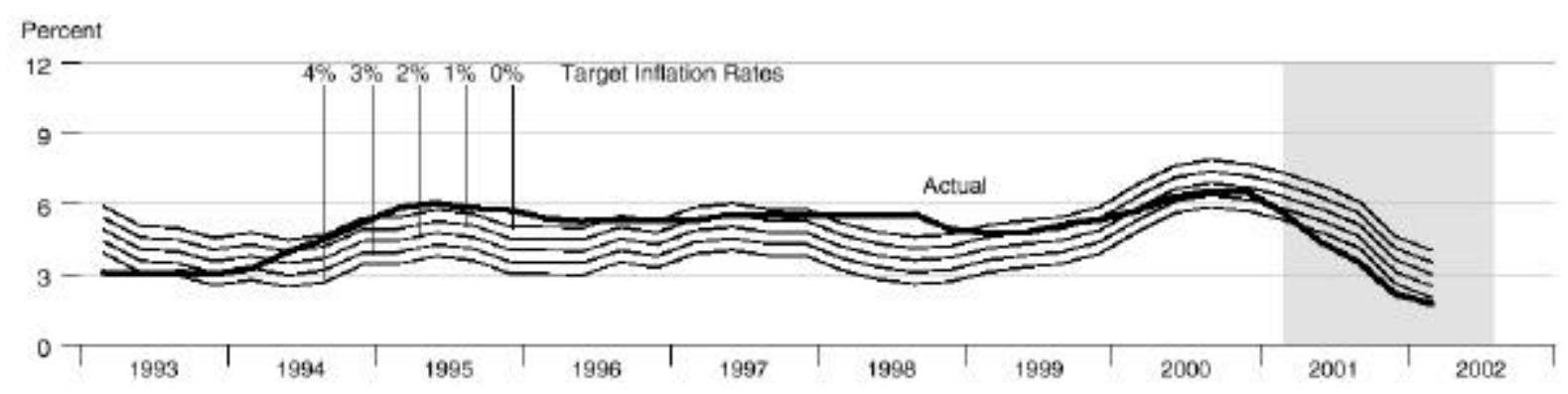

Figure 13: The implicit target rate of inflation

Of course, this pragmatic (or opportunistic) adjustment of the implicit inflation rate raises the question whether a rule whose parameters are themselves subject to cyclical revisions can still be called a rule, and whether it will elicit behaviour consistent with a rule or rather behaviour reflecting the perception of discretionary central bank policy.

\footnotetext{
${ }^{2}$ Monetary Trends, Federal Reserve Bank of St. Louis, August 2002, p. 10.
} 


\section{Liquidity traps, deflationary spirals and the backward-bending AD curve}

Just as money supply increases are no panacea in the regular IS-LM model, an MPR is not a panacea in the IS-MPR world. It is well known, though forgotten until recently, that a liquidity trap situation, i.e. a situation in which money demand becomes infinitely elastic, results in impotence, or at least difficulties in the conduct of monetary policy. It would seem, however, that an IS-MPR model provides somewhat deeper insight with less expenditure of analytical effort. In order to see this, recall how a liquidity trap has to be modelled in an IS-LM context. This implies that the LM curve exhibit a long flat segment before it starts to rise. The intersection of the IS curve with the LM curve occurs in the flat portion of the LM curve. This way of demonstrating the liquidity trap is alright as far as it goes, but it does not go very far, since a more realistic model would require an explicit account of inflation and deflation, and, consequently, the entire supply process. It can be done, but it is cumbersome, because it requires simultaneous attention to inflation and the price level and to the real and the nominal interest rates.

Fig. 15 shows a liquidity trap in an MPR environment. It describes a situation in which full employment would require a negative real interest rate. The upper left panel of the diagram exhibits the constraints to which monetary policy is subject. The nominal and real MPR invariably intersect on the interest axis. Due to the non-negativity constraint of the nominal interest rate, the MPR has a kink at the zero nominal interest rate level. Consequently, at the real interest corresponding to the zero nominal interest rate, the real MPR must have a kink as well. But, whereas the nominal MPR just becomes flat at a zero nominal interest rate, the real MPR starts rising again. Fig. 14 illustrates the nature of this constraint. Thus, regardless of the concrete shape of the MPR, the real MPR will have a kink at the inflation rate at which the nominal MPR meets with the inflation axis. At lower inflation rates, the real interest rate rises again along a line with slope -1 . That is, at least within this framework, the MPR is impotent at inflation rates below the $\mathrm{i}=0$ inflation rate. This has a profound effect on the $\mathrm{AD}$ curve since this curve will exhibit a kink as well. We get a backward-bending AD curve. The kink occurs at the inflation rate which corresponds to the lowest real interest rate, i.e. at the inflation rate where the nominal MPR hits the $\pi$ axis.

Taking account of the non-negativity constraint requires some slight modifications of the model. The nominal MPR now has a kink: 

(18) $\mathrm{i}=\mathrm{r}_{0}+(1+\mathrm{a}) \pi$
for $\pi>\pi_{c}=-\frac{r_{0}}{1+a}$
(19) $\quad i=0$
for $\pi \leq \pi_{c}=-\frac{r_{0}}{1+a}$

which implies

(20) $r=r_{0}+a \pi$

for $\pi>\pi_{c}=-\frac{r_{0}}{1+a}$

(21) $\mathrm{r}=-\pi$

for $\pi \leq \pi_{c}=-\frac{r_{0}}{1+a}$

To construct the $\mathrm{AD}$ curve, we assume an ad hoc IS curve:

(22) $\mathrm{Y}=\mathrm{K}-\beta \mathrm{r}$

IS curve

Fig. 15 constructs the $\mathrm{AD}$ curve resulting from these constraints.

Inserting equation 20 into the IS curve, yields the well-behaved section of the $\mathrm{AD}$ curve, i.e. the section where both the MPR and the IS curve determine the location and slope of the AD curve.

(23) $\mathrm{Y}=\mathrm{K}-\beta \mathrm{r}_{0}-\mathrm{a} \beta \pi \quad$ for $\pi>-\frac{\mathrm{r}_{0}}{1+\mathrm{a}}$

Below the critical inflation rate, the location and slope of the AD curve are determined uniquely by the IS curve. Just the length of the upward-sloping leg of the AD curve is determined by the MPR. This can be seen by plugging equation (21) into equation (22), a substitution which results in:

(24) $\mathrm{Y}=\mathrm{K}+\beta \pi$

$$
\text { for } \pi<-\frac{\mathrm{r}_{0}}{1+\mathrm{a}}
$$

The intersection of equations (23) and (24) is the critical rate of inflation below which control by monetary policy, in this model, ceases. This need not yet be an area of deflationary spiral, but control is taken over by the real demand sector. As long as inflation is between points $\mathrm{X}$ and $\mathrm{N}$, the system is stable. Once inflation has dropped below the level indicated by $X$, the system is out of control and gets into a deflationary spiral.

What can monetary policy achieve under these circumstances? Not much, actually, since point $\mathrm{X}$ is entirely determined by real supply and demand factors. Via $r_{0}$ 
monetary policy can extend or shrink the lower leg of the AD curve. In addition, it can determine the slope of the upper leg, but in order to shift down the lower leg, other instruments, or transmission mechanisms other than the classic interest rate mechanism, are required. The latter would be most welcome, but there is no way to achieve this by changing the parameters of the MPR. It looks as if monetary policy in general, and MPR-based monetary policy in particular, is a device for well-behaved times, but is of limited use in extreme situations.
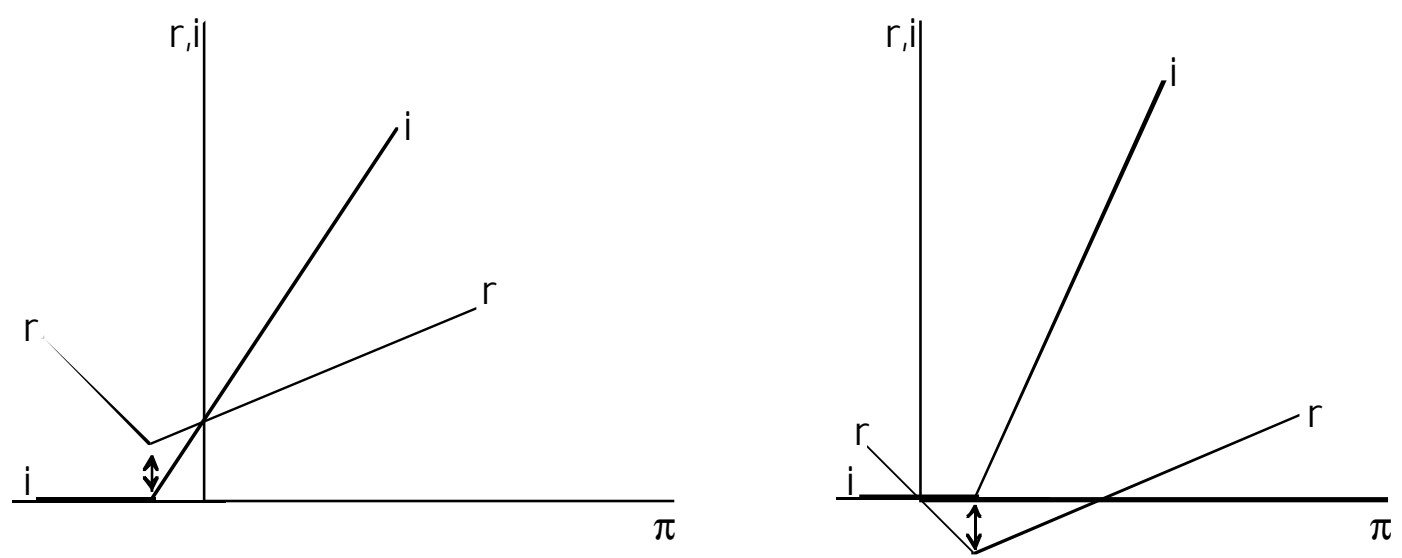

Figure 14: Two liquidity traps

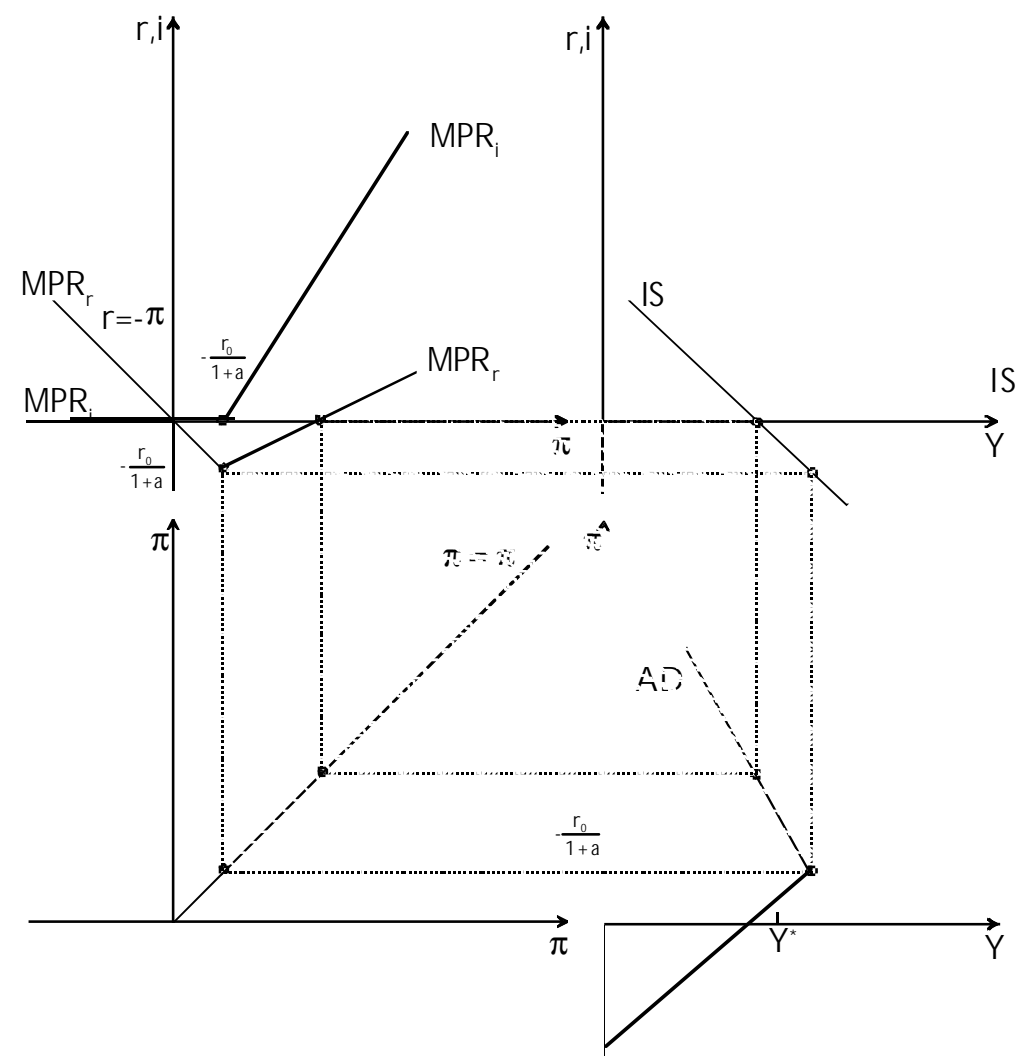

Figure 15: Liquidity trap and backward-bending AD curve 

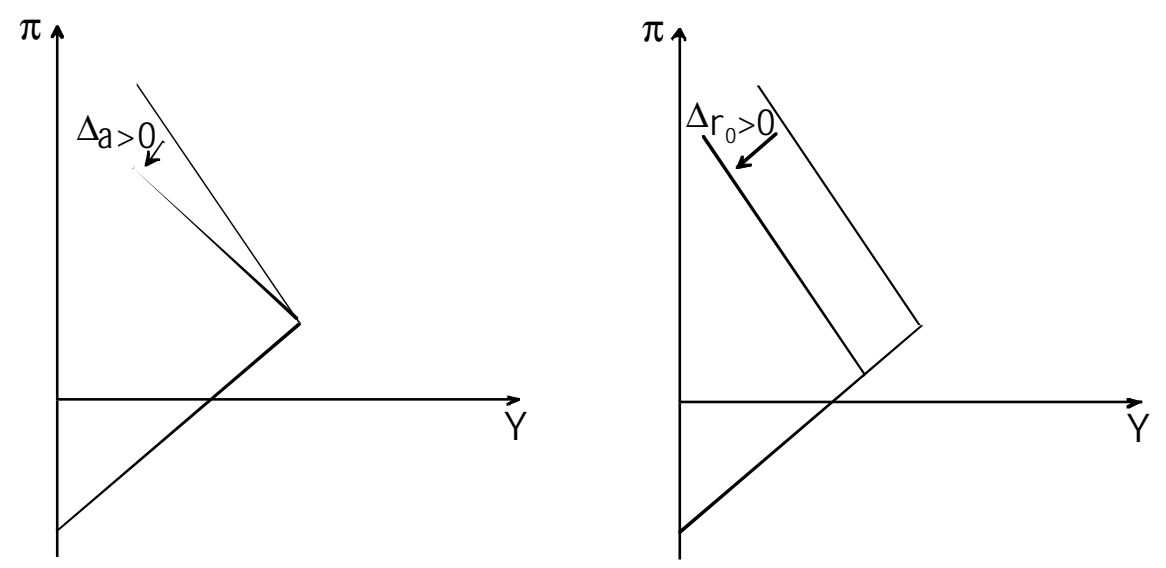

Figure 16: Effect of change in MPR on backward-bending AD curve

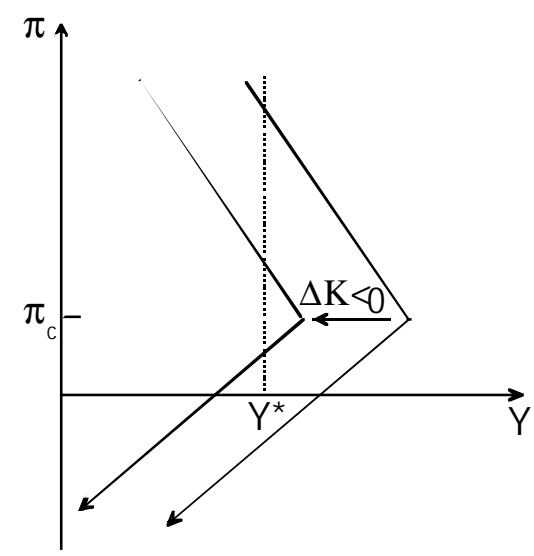

Figure 17: Effect of change of intersection of IS on backward-bending AD curve

Now, of course, this model cannot be the last word on liquidity traps and deflationary spirals. After all, the only transmission mechanism in the IS-MPR model that is considered here is the interest rate mechanism. It may well be that other transmission mechanisms remain intact even when the simple interest rate mechanism fails to work. Still, this model provides a transparent framework for pedagogically illustrating such statements about Japanese deflation as:

„Once inflation turned negative and short-term interest rates approached the zero-lower-bound, it became much more difficult for monetary policy to reactivate the economy. ${ }^{3}$

\footnotetext{
${ }^{3}$ Ahearne et al. (2002), abstract.
} 
„... an unfortunate aspect of the zero bound is that the worse the current downturn, the longer may be the period over which nominal short-term interest rates are expected to remain at zero, and the further into the future until the central bank can use its standard tools to stimulate aggregate demand. ${ }^{4}{ }^{4}$

Other transmission mechanisms notwithstanding, this model nicely and parsimoniously demonstrates how, at low inflation and low nominal interest rates, the interest rate mechanism, and hence the MPR-based monetary policy may fail to deliver. As is shown in Fig. 17, a rightward shift in the AD curve can only be engineered by direct or indirect action on the IS curve. One way to achieve this would be a money-financed increase in government purchases of goods and services.

How can an economy fall into a deflationary spiral? It will generally take both a negative demand shock and a negative inflation shock. And to get out of again, it will always take a strong demand shock. An accompanying inflation shock would help, of course.

\footnotetext{
${ }^{4}$ Clouse et al. (2000), p. 28.
} 


\section{The IS-MPR model for the open economy}

Romer (1999) makes an attempt to adapt the model to the requirements of an open economy. To this effect, he introduces a current account surplus (NX) and a net foreign investment (NFI) equation. He proposes a model that we can stylise in the following fashion:

(27) $r_{t}=r_{0}+d\left(Y_{t}-Y_{t}^{*}\right)$

IS open

FEE

MPR

The first equation is a straightforward open economy IS curve. The extra terms all concem the current account surplus. The latter is assumed to rise with world income and with the real exchange rate, REX. The Marshall-Lemer condition is assumed to be satisfied, hence $\mathrm{x}_{2}>\mathrm{m}_{2}$. The second equation depicts foreign exchange (flow) equilibrium. The left hand-side again describes the current account surplus. The righthand side models the desired net foreign investment (current international lending) as a function of the real interest disparity between the domestic economy and the world economy. Foreign exchange flow equilibrium implies equality of the current and the capital account. This simple model is very easy to handle. Two things should be noted. First, in the current account, a term denoting the effect of domestic income on the current account surplus is missing. Second, inflation is missing from the MPR. The MPR includes only output. These apparently innocuous simplifications are not purely fortuitous, In fact, they greatly simplify the analysis. But they come at a price.

All interactions can be drawn in one single set of three diagrams. As specified by this model, the MPR looks very much like an LM curve, though, of course it isn't one. Instead of representing money market equilibrium with given money supply, it exclusively represents central bank behaviour. Whereas the LM curve depicts emergent market behaviour, the MPR is a map of purposeful behaviour of one single actor. To determine equilibrium, we can solve the FEE condition for $x_{1} Y^{w}$ and substitute into the IS open condition. This yields an IS-FEE locus of the following shape:

$Y_{t}=\frac{1}{1-c}\left(-c T+G+\Gamma+\delta r_{t}^{*}\right)-\frac{b+\delta}{1-c} r_{t}$

IS-FEE locus 
Of course, there is more to this relationship than meets the eye. Indeed, every point on the curve corresponds to a different real exchange rate, the highest REX (i.e. the lowest values of the domestic currency) being to the south-east, the lowest to the north-west.

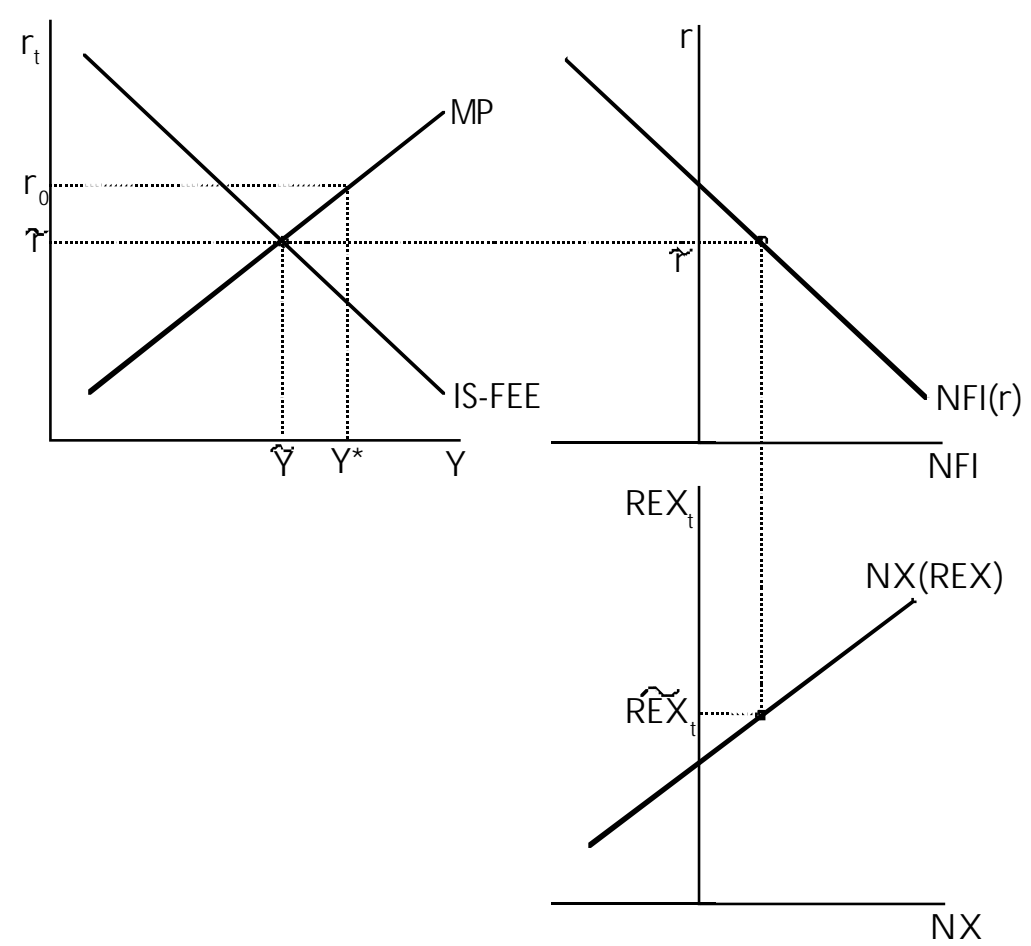

Figure 18: The Romer (1999) open economy model

Experiments with this model are extremely straightforward. The show essentially takes place in the $(Y, r)$-quadrant. The two external quadrants are mere appendices.

Several features deserve to be noted:

a. It seems as if the central bank has perfect control of the real interest rate. Of course, this is not strictly the case, for the IS-FEE locus depends on the interest elasticity of the NFI curve, which makes it flatter than the IS curve of a closed economy. Still, Romer emphasises that this elasticity is low enough to warrant a definitely finite slope of the net foreign investment curve. So the central bank retains considerable control of the real interest rate despite the presence of international investment opportunities. To be sure, the assumption that the central bank has control of the real interest rate underlies the whole approach, anyway, an assumption which may not be shared by everybody. Given the stickiness of inflation and possibly inflation expectations relative to the flexibility of short-run interest rates, one can make a case for the possibility of real interest manipulation 
by the central bank in a closed economy. But it is one thing to assume that, in the short run, in a closed economy, the real interest rate may be influenced, and quite another to assume that this power is not significantly diluted by the presence of international capital transactions.

b. Under these assumptions, the real exchange rate is under fairly close control of the central bank notwithstanding the openness of the economy.

c. Moreover, the model as it stands, also implies that both fiscal impulses and monetary policy (in the sense of the setting of the MPR) are fairly effective even in an small open economy. In the absence of a natural rate attractor mechanism operating via inflation the model even suggests that both types of demand management policies, fiscal and monetary may well have enduring effects on output and employment. To be sure, the model is not intended to depict long-run equilibria, but it would be nice if there were provisions in the model itself indicating that the equilibrium in question is not sustainable and where the system is likely to converge.

All this can be justified by pointing to the fact that the model has no ambition to explain anything beyond the short run. Still, the model would be considerably more attractive for teaching purposes and more in line with the explanatory goal of the closed economy version would it include the following ingredients:

a. A plausible mechanism producing temporary equilibria the string of which ultimately converges to a steady state consistent with the natural rate hypothesis. This would require a more explicit model of the supply side which would include some kind of inflation dynamics.

b. A term, in the current account equation, representing the effect of domestic income on imports, and hence on the current account surplus.

c. A rigorous stock-adjustment specification of the net foreign investment function, or, alternatively, an arbitrage condition. As formulated by Romer, the NFI function amounts to a permanent flow relationship whereas foreign lending, by its very nature, is a stock adjustment decision which is driven not by a stable flow demand but rather by a portfolio demand.

Requirements a. and b. can fairly easily be implemented. They can be met by inserting an extra term into the current account expression, replacing the MPR by an MPR contingent on the rate of inflation, and by introducing some short-run aggregate 
supply process. For the latter purpose, we can draw on the closed economy short-run aggregate supply process.

Such a model could look as follows:

(28) $Y_{t}=\mathrm{c}(1-\tau) Y_{t}-c T_{0}+G_{0}+\bar{I}-b r_{t}+x_{1} Y^{W}+\left(x_{2}-m_{2}\right) R E X-m_{1} Y_{t}$

IS open

(29) $x_{1} Y^{W}+\left(x_{2}-m_{2}\right) R E X-m_{l} Y_{t}=d\left(r_{t}^{*}-r_{t}\right)$

FEE

(30) $r_{t}=r_{0}+a \pi_{t}$

MPR

(31) $\pi_{t}=\pi_{t-1}+?\left(Y_{t-1}-Y^{*}\right)$

SRAS

Solving the IS relationship for $Y_{t}$ and the FEE relationship for $r_{t}$ yields the general shape of IS and FEE in this model.

$$
\begin{aligned}
Y_{t}= & \frac{1}{1-c(1-t)+m_{l}}\left[-c T_{0}+G_{0}+\bar{I}+x_{l} Y^{W}\right]-\frac{b}{1-c(1-t)+m_{l}} r_{t} \\
& +\frac{x_{2}-m_{2}}{1-c(1-t)+m_{l}} R E X_{t}
\end{aligned}
$$

(33) $r_{t}=r_{t}^{*}-\frac{x_{1}}{d} Y^{W}-\frac{x_{2}-m_{2}}{d} R E X_{t}+\frac{m_{1}}{d} Y_{t}$

FEE red.

Substituting the current account surplus side of the FEE relationship into the IS curve yields the new IS-FEE relationship.

(34) $Y_{t}=c(1-t) Y-c T_{0}+G_{0}+\bar{I}_{t}-b r_{t}+d\left(r_{t}^{W}-r_{t}\right)$

(35) $Y_{t}=\frac{1}{1-c(1-t)_{1}}\left[-c T_{0}+G_{0}+\bar{I}+\delta r_{t}^{W}\right]_{t}-\frac{b+\delta}{1-c(1-t)} r_{t}$

This can now be translated into graphical form. 


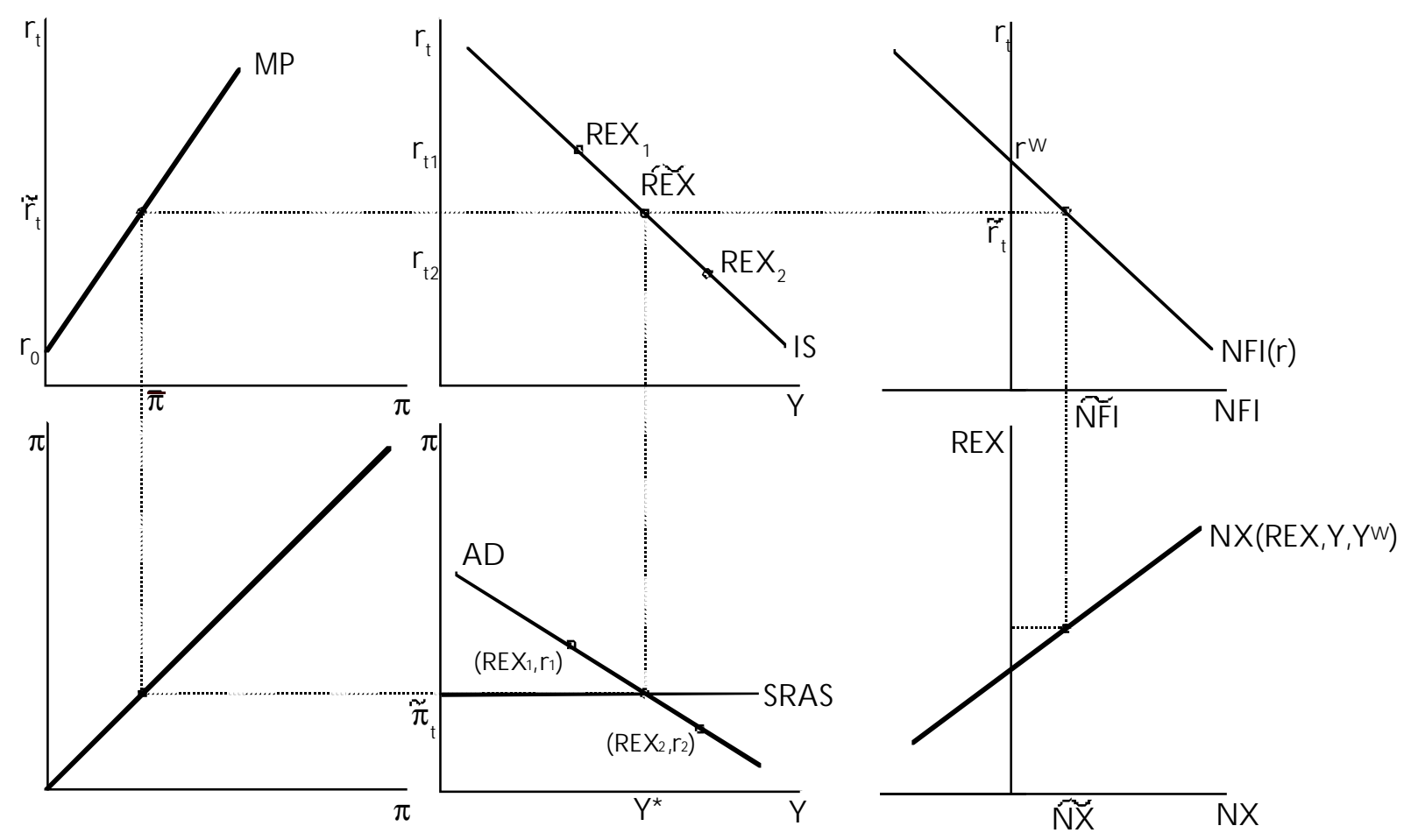

Figure 19: Comparative steady state (normal case)

Steady state and impact effects can easily be derived.

a. Change in MPR: A move towards a looser monetary policy, e.g. a reduction of $r_{0}$, moves the $\mathrm{AD}$ curve to the right, and hence affects only the steady state magnitudes of inflation and the nominal interest rate. Real variables, including real prices such as the real interest rate and the real exchange rate return to their initial steady state values. The impact effect is more intricate. At first, the real interest rate declines due to the downward shift of the MPR. This causes a movement down the IS-FEE curve so that income $\mathrm{Y}$ increases and the real exchange rate, REX, rises as well (amounting to a real depreciation of the currency). Hence, the NX schedule shifts up. Net exports and net foreign investment rise temporarily. There are no lasting effects on real magnitudes. 


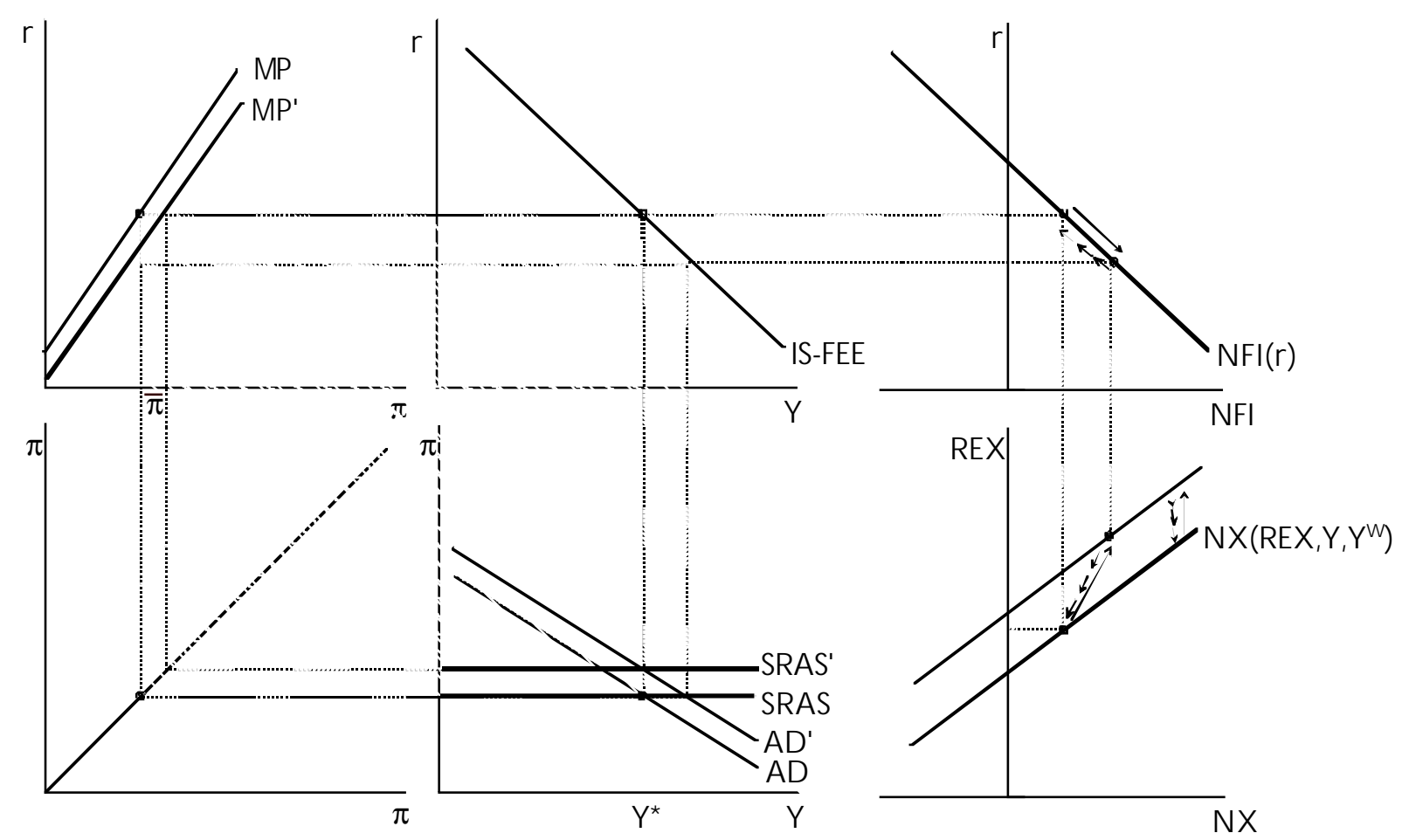

Figure 20: Change in MPR

b. Domestic fiscal impulse: An expansion of government expenditure on goods and services moves the IS-FEE and the AD curves to the right. In the steady state, we will observe an increase in the real interest rate and a decrease in the real exchange rate (appreciation). Inflation will rise unless the MPR is adjusted to counteract the higher inflation. Net foreign investment and net exports will decline due to a crowding out of exports in favour of government purchases. The impact effect will show a temporary increase in output. The real exchange rate will temporarily increase (depreciation). There will thus occur an effect of reculer pour mieux sauter in the real exchange rate: first a depreciation, and subsequently a reappreciation beyond the initial level. 


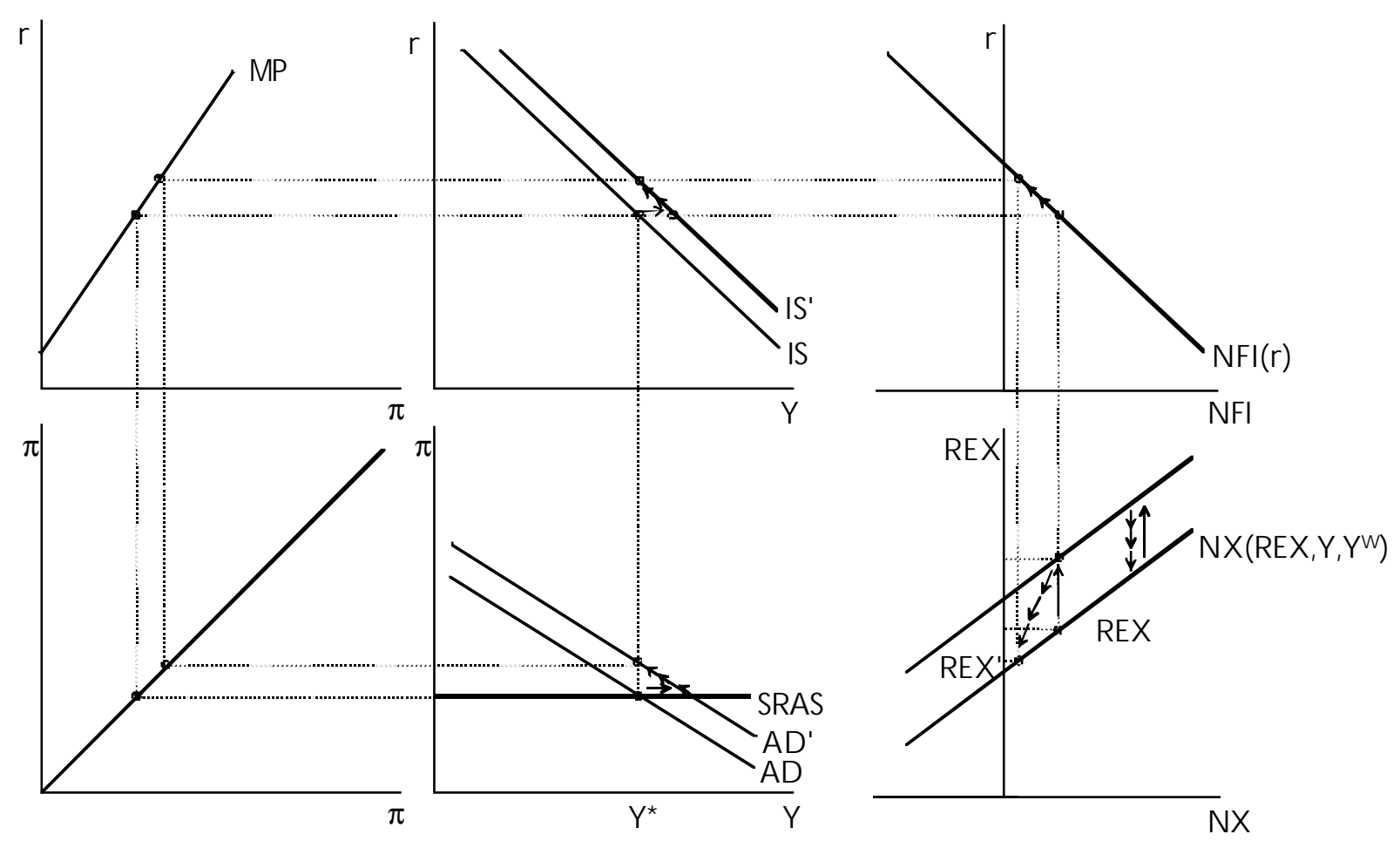

Figure 21: Domestic fiscal impulse

c. Change in world real interest rate: This shock moves the IS-FEE curve, and hence the AD-curve, to the right. This shift will ultimately raise the real interest rate and inflation. The real exchange rate will not be affected. This new steady state is the result of a roundabout process. At first, output rises, which, given the new NFI curve, results in an increase in the real exchange rate (depreciation). The positive output gap now increases inflation which counteracts the initial expansion. The NX curve which had shifted inwards under the impact of the positive output gap little by little shifts back to its initial position. So does the real exchange rate. 


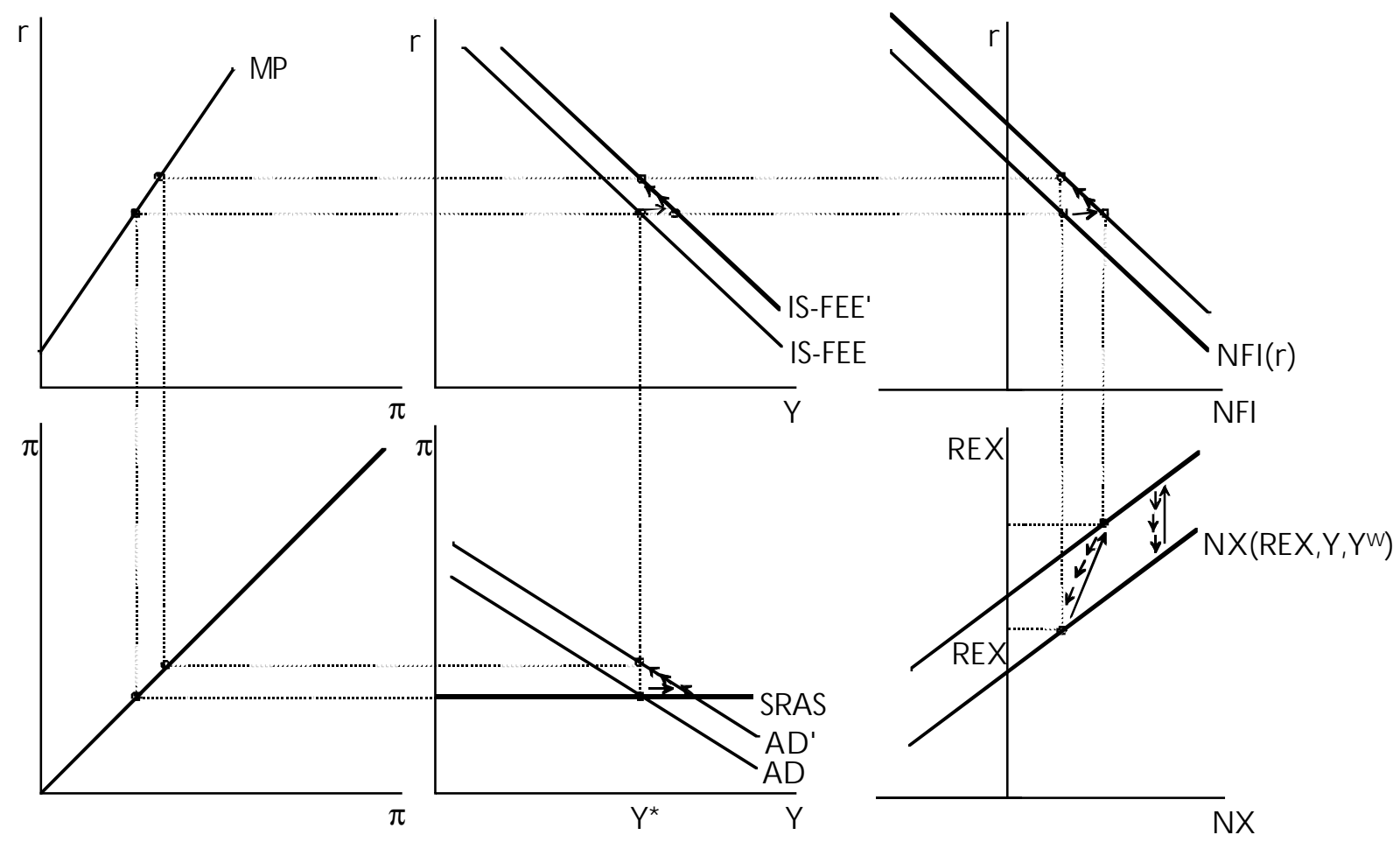

Figure 22: Change in world interest rate

d. Change in world income: Curiously, and surprisingly, this shock entails no adjustment process. The real exchange rate drops immediately (appreciation) to its new position. Two countervailing effects cancel each other so that the IS-FEE curve does not have to move. Since the foreign exchange market is permanently cleared, the expansive effect on aggregate demand is immediately, and exactly, cancelled by the increase in the real exchange rate. 


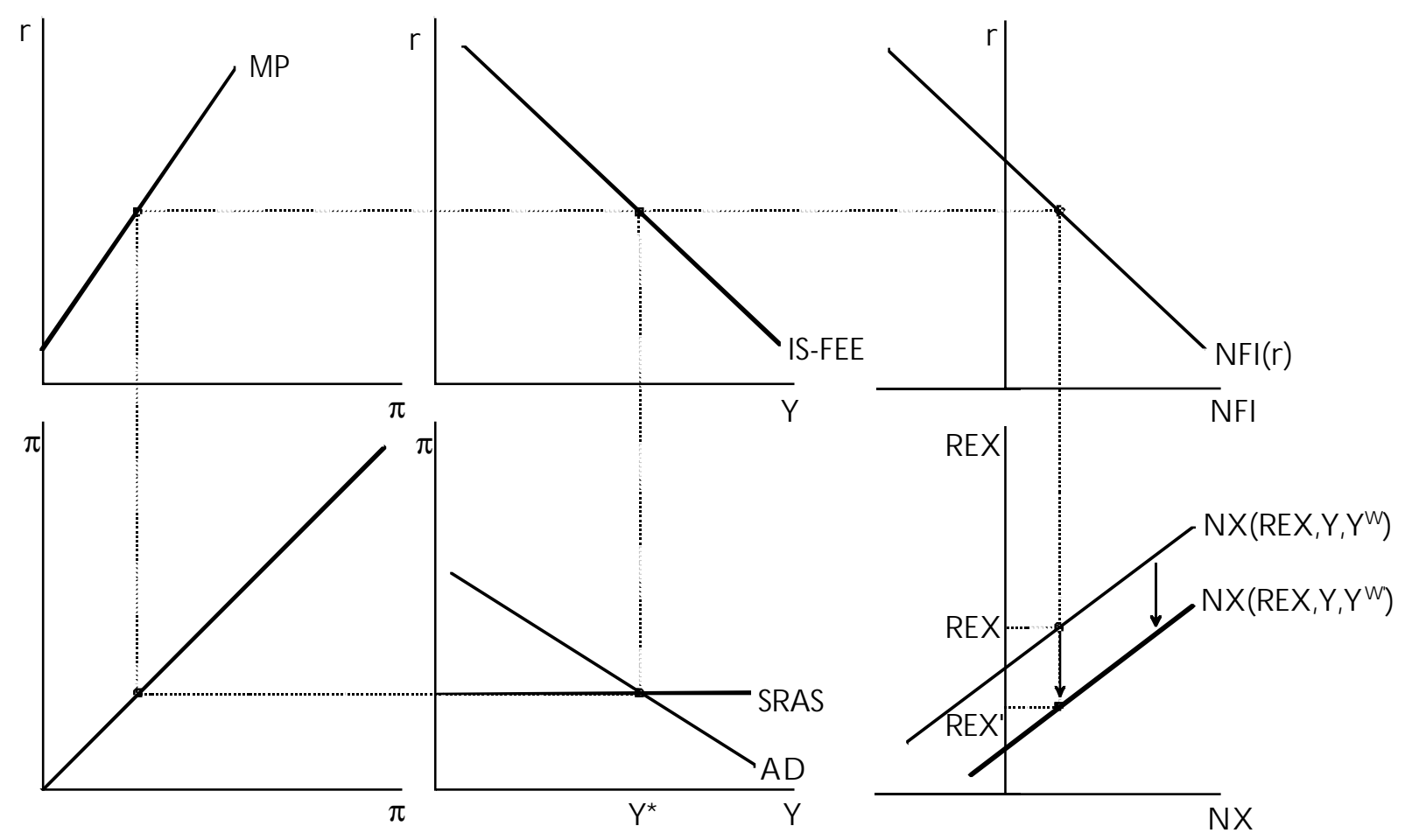

Figure 23: Change in world income

The major weakness of this model remains the pure flow specification of foreign lending transactions. As mentioned earlier, this might give rise to erroneous ideas. At least in the steady state, there ought to be no net capital movements in a stationary economy such as the one generally used in introductory macro texts. This approach, though attractive due to its simplicity, is not quite satisfactory. The major weakness resides in the modelling of international lending. The domestic economy still has full control of the real (and nominal) interest rate and, indirectly, of the exchange rate. It is unsatisfactory to assume a stable flow of international lending. International lending is a portfolio decision and hence a stock decision. The assumption, in an inherently dynamic model such as the IS-MPR model, that we can simply move along a net foreign investment locus without undergoing shifts of the NFI curve itself is implausible if not genuinely misleading. One might, in defence of this simplification, argue that we are committing no worse sin against orthodox stock-flow hydraulics than we do in using a static investment function instead of modelling the entire stock adjustment process. Given the differential speeds of the two processes, the sin is less serious in the case of investment than in that of international lending. Real investment is subject to physical inertia whereas international lending is an instant affair and therefore should not be "tamed" for the sole purpose of simplicity. The simplicity that 
might be called for in such a case is more likely to be the assumption of perfect arbitrage between the loan markets.

\section{How does the IS-MPR model measure up to the ten commandments?}

It is time to take stock and evaluate how well the new family of models performs in terms of the desirable features of a teaching model.

1. Regarding the training in thinking in terms of interacting markets, the IS-MPR and its derivatives are certainly no worse, but perhaps also no better, than the traditional model. To be sure, in this exposition, we have omitted the labour market, but this is omission only has to do with our aim to pinpoint the critical issues. Inserting a conventional model of the labour market poses no problem whatsoever. Moreover, it has been shown that the money market can be added without loss of essence. Yet, the model is less than rigorous regarding e.g. Walras' Law, but so is the conventional model. The overall budget constraint is not discussed, nor can it be without addition of a much more intricate apparatus.

2. The stock-flow hydraulics is the Achilles' heel of the IS-MPR model. There is really no stock-flow dynamics at all. It is as if the path from period to period occurs exclusively via inflation dynamics. This is particularly problematic in the versions dealing with the open economy since it precludes any plausible analysis of the standard exchange rate systems. Of course, it is also awkward in the context of the capacity effect of investment. The latter, however, is a birth defect of most introductory models of investment. It is due to the didactic division of labour between short- and long-run macroeconomics, or macroeconomics in the narrow sense on the one hand and growth theory on the other.

3. The proponents of the IS-MPR model (Walsh 2002) regard as one of the great strengths of the new model the fact that the student is spared the trouble to first get acquainted with the effects of the price level and subsequently go through the tedious work of converting a model with a price level variable into one with an inflation rate. This shortcut certainly is a mixed blessing once one thinks about modelling the open economy. So far, simple teaching models of the open economy, e.g. Dornbusch's (1976) overshooting model, have been formulated in terms of steady state price levels, not steady state inflation. Consequently, inflation 
and exchange rate dynamics was no more than a transitory episode between two steady state levels. The analytics of the exchange rate in a world of steady state inflation is certainly less than straightforward, and the models proposed so far and the one discussed in this paper do not go very far, or far enough, to solve these problems in a beginner-friendly fashion. What appears a tolerable, even elegant, short-cut in the closed economy is much harder to swallow in the open economy.

4. Expectations generally enter our teaching models via the short run supply process. This can be done here, too. We have not done so above, but this choice was not dictated by any kind of necessity but merely due to our endeavour to keep the model simple. But the problem can be remedied without introducing excessive complications. More serious is the omission of expectations in the definition of the real rate of interest and in the determination of the exchange rate. This defect is not easily remedied. But then, most macroeconomics textbooks don't apply much care in making explicit the role of expectations in the real interest rate and consequently in the investment function.

5. Explicit intertemporal relationships are almost completely absent from the model. This, too, is no peculiarity of the present model. Rather it is a feature shared with most introductory models. Intermediate texts make only parsimonious use of intertemporal relationships.

6. Compared with standard texts, the model outlined in this paper fairly early stresses the relevance of the difference between nominal and real interest and exchange rates. Whether the type of modelling this difference is actually beyond criticism is another matter. A major weakness which should not be swept under the rug resides in the fact that the difference is defined without resorting to expectations.

7. The model performs pretty well in terms of ability to demonstrate the multi-market effects of the standard catalogue of shocks. The inability of depicting money demand shocks is no weakness given that, under a strict monetary policy rule, money demand shocks are by definition neutralised at once so that they cannot affect the real markets. The same holds for money supply shocks in the shape of multiplier shifts. As was demonstrated in the relevant section, it is straightforward to demonstrate what goes on behind the scenes, on the money market, but there is no need to clutter the model with these details as long as one remains within the straightjacket of a monetary policy based on a mechanical MPR. 
8. Regarding demand management policies, the model perfectly matches the amount of realism generally found in intermediate texts. And the blind spots are largely the same, too: E.g. lack of an explicit relationship incorporating the financing aspect of fiscal policy; i.e. generally lack of explicit government budget constraint. Equally, wealth effects are absent, but where do we find wealth effects in conventional macro texts? Obviously also, there is no way to simulate a once-and-for-all money supply shock, but this is no real drawback because the model is precisely designed to demonstrate the operation of the economy under an MPR, which excludes arbitrary discretionary money supply shocks.

9. The natural rate and the superneutrality hypotheses are respected though, of course, not really founded. They are imposed on the model rather than carefully underpinned. Again, we are in excellent company since conventional teaching models do likewise. What appears as a lacuna is a reflection of the traditional division of labour between business cycle macro and growth macro. The attractor mechanism which automatically brings the system back to potential is a faithful copy of standard models. It conveys the consensus of the discipline.

10. There can be no doubt that the open economy version is the crucial weakness of the model. It is definitely not satisfactory. There are reasons for believing that the open economy, for all intents and purposes, does not admit of an independent interest rate policy, at least for a small open economy. A proper model of the open economy would require a rigorous stock flow or arbitrage relationship. 


\section{Concluding remarks}

This article has attempted to show how a monetary policy rule of the kind currently being implemented by central banks can be plugged into a simple macroeconomic teaching model. The resulting family of models is no more difficult to handle than a regular IS-LM model and its customary derivatives. Also, the new family of teaching models fits perfectly well into an IS-LM framework, so that the teacher is spared the difficult either-or decision. We feel that the new family of models should not crowd out the conventional IS-LM family but should rather complement them. It is more judicious to treat the IS-MPR models as a sub-species of conventional models than to claim the whole territory for it. The IS-MPR models more or less adequately depict a particular monetary policy environment but they are definitely less general. They allow a shortcut which is fully warranted under the particular monetary policy regime. But the shortcut comes at the price of a lack of flexibility. And since no one knows what the future will bring in terms of monetary policy, there can be made a valid case for a more general model that accommodates both, policy rules different from Taylorinspired ones and discretionary monetary shocks. Not satisfactory at all yet is the open economy version of the IS-MPR model. 


\section{List of Symbols}

\section{Latin Letters}

$\mathrm{a}$

$\mathrm{b}$

C

d

e

$\mathrm{h}$

NFI net foreign investment (net capital exports)

NX current account surplus

P domestic price level

r real interest rate

REX real exchange rate

t time period subscript

$\mathrm{T}$

$\mathrm{X}_{1}$

$\mathrm{X}_{2}$

$\mathrm{Y}$

$\mathrm{Y}^{\mathrm{W}}$ components of demand) ( $\mathrm{b}>0)$ $(d>0)$

expectation

investment demand

nominal interest rate

income sensitivity of money demand $(\mathrm{k}>0)$

nominal (central bank) money supply

tax revenue Marshall-Lemer condition is satisfied: $\mathrm{x}_{2}>0$ )

output, income

world real income real interest response of MPR to variations in inflation $(a>0)$

interest sensitivity of investment (or more generally, of all interest-sensitive

marginal propensity to consume of dispensable income $(1<\mathrm{c}<0)$

Output gaps parameter in Taylor rule, real interest response to output gaps

nominal interest sensitivity of money demand

demand for (central bank) money in real terms

sensitivity of current account surplus for income in rest of the world $\left(\mathrm{x}_{1}>0\right)$

sensitivity of current account surplus to real exchange rate (assuming 


\section{Greek Letters}

$\delta \quad$ sensitivity of net foreign investment to differential between foreign and domestic real interest rate

$\gamma \quad$ inflation response to output gaps

$\lambda \quad$ adjustment parameter of inflation expectations

$\pi$ rate of inflation

$\theta \quad$ adjustment parameter in Lucas-supply function

$\tau \quad$ marginal tax rate 


\section{Bibliography}

Ahearne Alan, Joseph Gagnon, Jane Haltmaier, and Steve Kamin (2002) "Preventing deflation: Lessons from Japan's Experience in the 1990s", Board of Governors of the Federal Reserve System, International Finance Discussion Paper, No. 729, June.

Barro, Robert J. (1984) “Macroeconomics”, John Wiley \& Sons Inc..

Clouse James, Dale Henderson, Athanasios Orphanides, Damid Small, and Peter Tinsley (2000) "Monetary policy when the nominal short-term interest rate is zero", Board of Governors of the Federal Reserve System, Finance and Economic Discussion Series, 2000-51, November.

Danthine Jean-Pierre (1998) „À la poursuite du Graal : le successeur d'IS-LM est-il identifié ?", L'Actualité économique, Revue d'analyse économique, Vol. 74, No. 4, pp. 607-620, December.

Dombusch, Rudiger (1976) "Expectations and exchange rate dynamics", Journal of Political Economy, Vol. 84, 1161-1176.

Frank Robert, Bernanke Ben (2001) “Principles of Economics”, McGraw-Hill Irwin.

Federal Reserve Bank of St. Louis, Monetary Policy Trends, various issues.

Johnson David R. (2001) "What is taught in the first year Macroeconomics: Changes over the last twenty years", Laurier Business and Economics, Department of Economics, Working Paper Series, 01-03, November.

Meltzer Allan H., Brunner Karl (1972) "Money, debt and economic activity", Journal of Political Economy, Vol. 80, 951-977.

Romer David (1999) "Short-Run Fluctuations", University of Carlifornia, Berkeley, August.

Romer David (2000) "Keynesian Macroeconomics without the LM Curve", Journal of Economic Perspectives, Vol. 14, No. 2, Spring 2000.

Stockman Alan C. (1996) "Introduction to Macroeconomics", The Dryden Press.

Taylor John B. (2001) "Economics”, Houghton Mifflin Company, Third Edition.

Taylor John B. (2000) „Teaching Modern Macroeconomics at the Principles Level”, American Economic Review, Vol. 90, No. 2, May 2000. 
Walsh Carl E. (2002) "Teaching Inflation Targeting: An Analysis for Intermediate Macro", Journal of Economic Education, Vol. 33, No 4, Fall, 333-347. 